\title{
Local stresses, dyke arrest and surface deformation in volcanic edifices and rift zones
}

\author{
Agust Gudmundsson $\left({ }^{1}\right)$ and Sonja L. Brenner $\left({ }^{2}\right)$ \\ ${ }^{1}{ }^{1}$ Department of Structural Geology and Geodynamics, Geoscience Centre, University of Göttingen, Germany \\ $\left.{ }^{2}{ }^{2}\right)$ Department of Earth Sciences, University of Bergen, Norway
}

\begin{abstract}
Field studies indicate that nearly all eruptions in volcanic edifices and rift zones are supplied with magma through fractures (dykes) that are opened by magmatic overpressure. While (inferred) dyke injections are frequent during unrest periods, volcanic eruptions are, in comparison, infrequent, suggesting that most dykes become arrested at certain depths in the crust, in agreement with field studies. The frequency of dyke arrest can be partly explained by the numerical models presented here which indicate that volcanic edifices and rift zones consisting of rocks of contrasting mechanical properties, such as soft pyroclastic layers and stiff lava flows, commonly develop local stress fields that encourage dyke arrest. During unrest, surface deformation studies are routinely used to infer the geometries of arrested dykes, and some models (using homogeneous, isotropic half-spaces) infer large grabens to be induced by such dykes. Our results, however, show that the dyke-tip tensile stresses are normally much greater than the induced surface stresses, making it difficult to explain how a dyke can induce surface stresses in excess of the tensile (or shear) strength while the same strength is not exceeded at the (arrested) dyke tip. Also, arrested dyke tips in eroded or active rift zones are normally not associated with dyke-induced grabens or normal faults, and some dykes arrested within a few metres of the surface do not generate faults or grabens. The numerical models show that abrupt changes in Young's moduli (stiffnesses), layers with relatively high dyke-normal compressive stresses (stress barriers), and weak horizontal contacts may make the dyke-induced surface tensile stresses too small for significant fault or graben formation to occur in rift zones or volcanic edifices. Also, these small surface stresses may have no simple relation to the dyke geometry or the depth to its tip. Thus, for a layered crust with weak contacts, straightforward inversion of surface geodetic data may lead to unreliable geometries of arrested dykes in active rift zones and volcanic edifices.
\end{abstract}

Key words dyke injection - dyke arrest - crustal stresses - crustal layering - surface deformation volcanic hazard

\section{Introduction}

What are the mechanical conditions that make it possible for magma to flow from a source chamber to the surface of a volcano, resulting in

Mailing address: Dr. Agust Gudmundsson, Department of Structural Geology and Geodynamics, Geoscience Centre, University of Göttingen, Goldschmidtstrasse 3, 37077 Göttingen, Germany; e-mail: Agust.Gudmundsson@gwdg.de an eruption? Alternatively, what are the necessary and sufficient conditions for a volcanic eruption to occur? The answers to these questions are of fundamental importance in volcanology; not only because they improve our understanding of how volcanoes work, but also because they must be known in order to assess volcanic risks during unrest periods in rift zones and volcanic edifices.

Field observations indicate that almost all eruptions in volcanic edifices and rift zones are supplied with magma through fractures that are generated by magmatic overpressure. It follows that the main mechanical condition for a volcanic eruption to occur is that an overpressured magma-filled fracture is able to propagate to the 


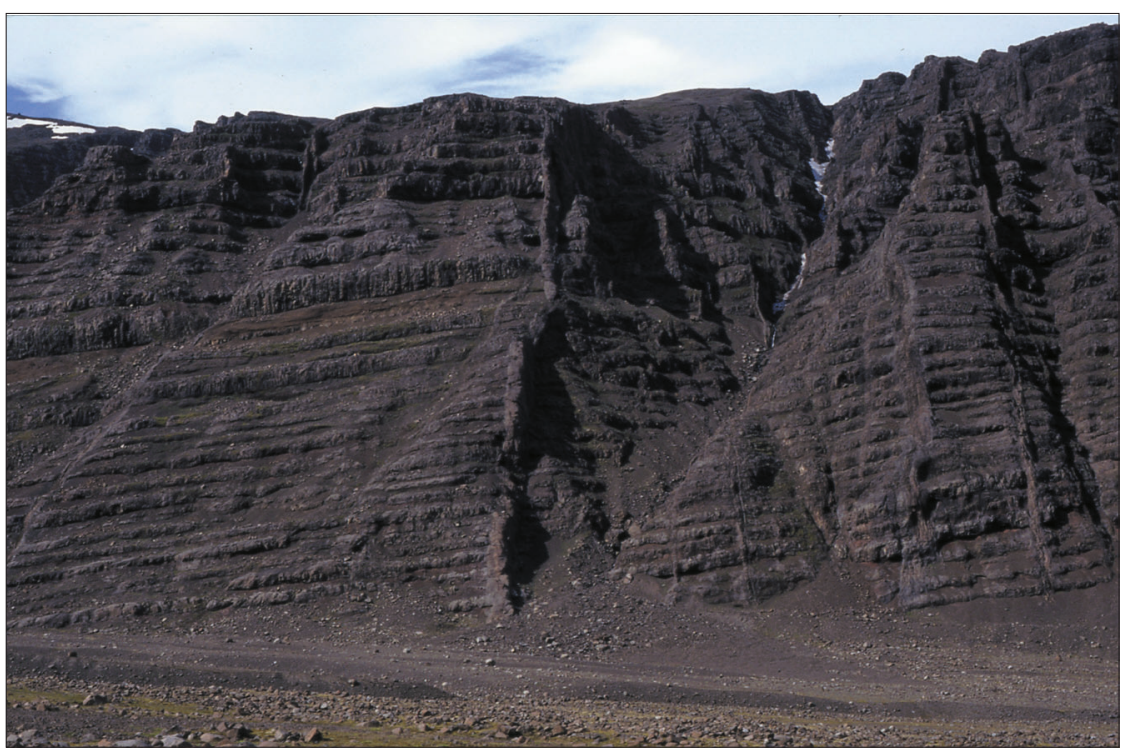

Fig. 1. $400 \mathrm{~m}$ thick Tertiary pile of lava flows, sediments and pyroclastic rocks in the valley of Vidbordsdalur in Southeast Iceland. View northeast, the general dip of the pile increases by $2-3^{\circ}$ from its top to the bottom. The pile is dissected by dykes, some of which are arrested, that reach thicknesses of up to $13 \mathrm{~m}$.

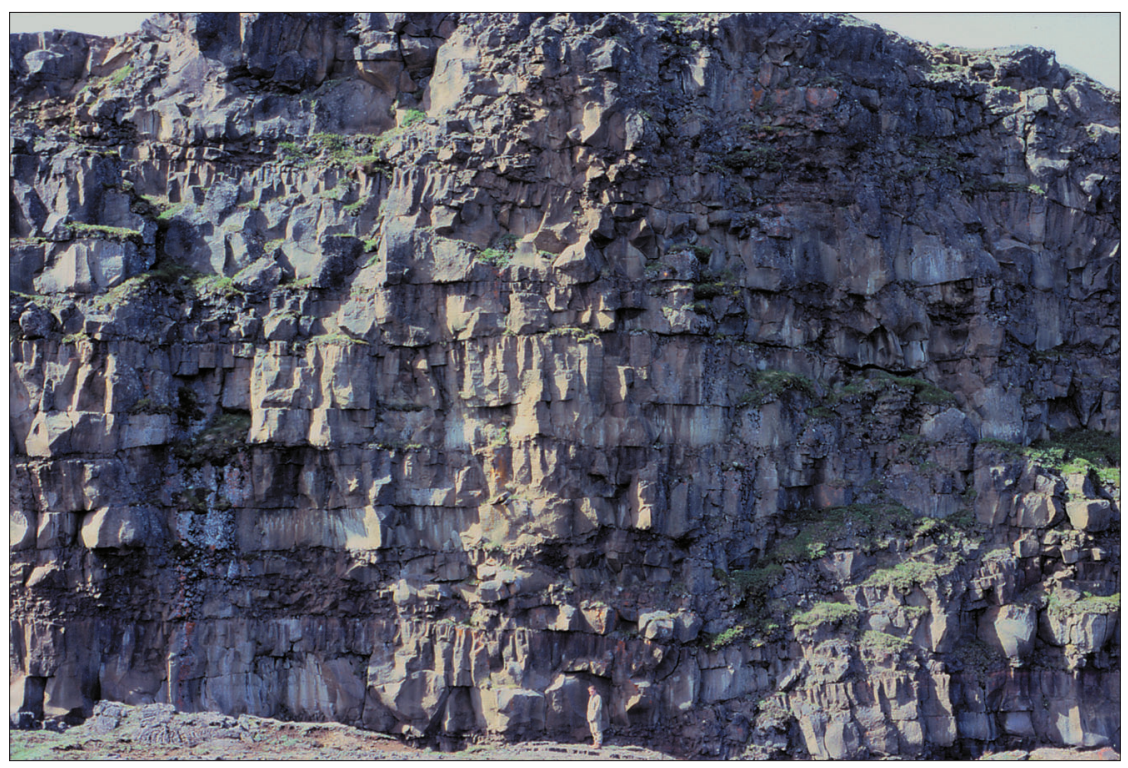

Fig. 2. Horizontal contacts between flow units and vertical columnar joints in a thick pahoehoe flow. Dykes that meet with such contacts commonly become offset or arrested. This 20 -m-tall wall (see the person for scale) belongs to a normal fault that dissects the Krafla Volcanic System of the Holocene rift zone in North Iceland (cf. fig. 5). 
surface. Field observations, however, also show that many magma-filled fractures never make it to the surface but rather solidify as arrested dykes (Gudmundsson, 2002). Many dykes have their tips arrested in essentially homogeneous and isotropic rock bodies, whereas others are arrested in heterogeneous and anisotropic rock bodies, particularly at contacts in layered rocks.

Most volcanic edifices and rift zones are composed of layered rocks (fig. 1). The layers are normally with very different mechanical properties. For example, there are commonly soft (low
Young's moduli) sedimentary and pyroclastic layers alternating with stiff (high Young's moduli) lava flows and intrusions. Furthermore, many layer contacts are weak (non-welded) or even open, particularly at shallow depths (fig. 2). When a dyke meets with weak or open contacts, or layers of contrasting mechanical properties, it normally becomes either offset (fig. 3) or arrested (fig. 4).

Thus, observational data show that dykes commonly become arrested or, more generally, offset on meeting with contacts between layers of contrasting mechanical properties in volcanic edi-
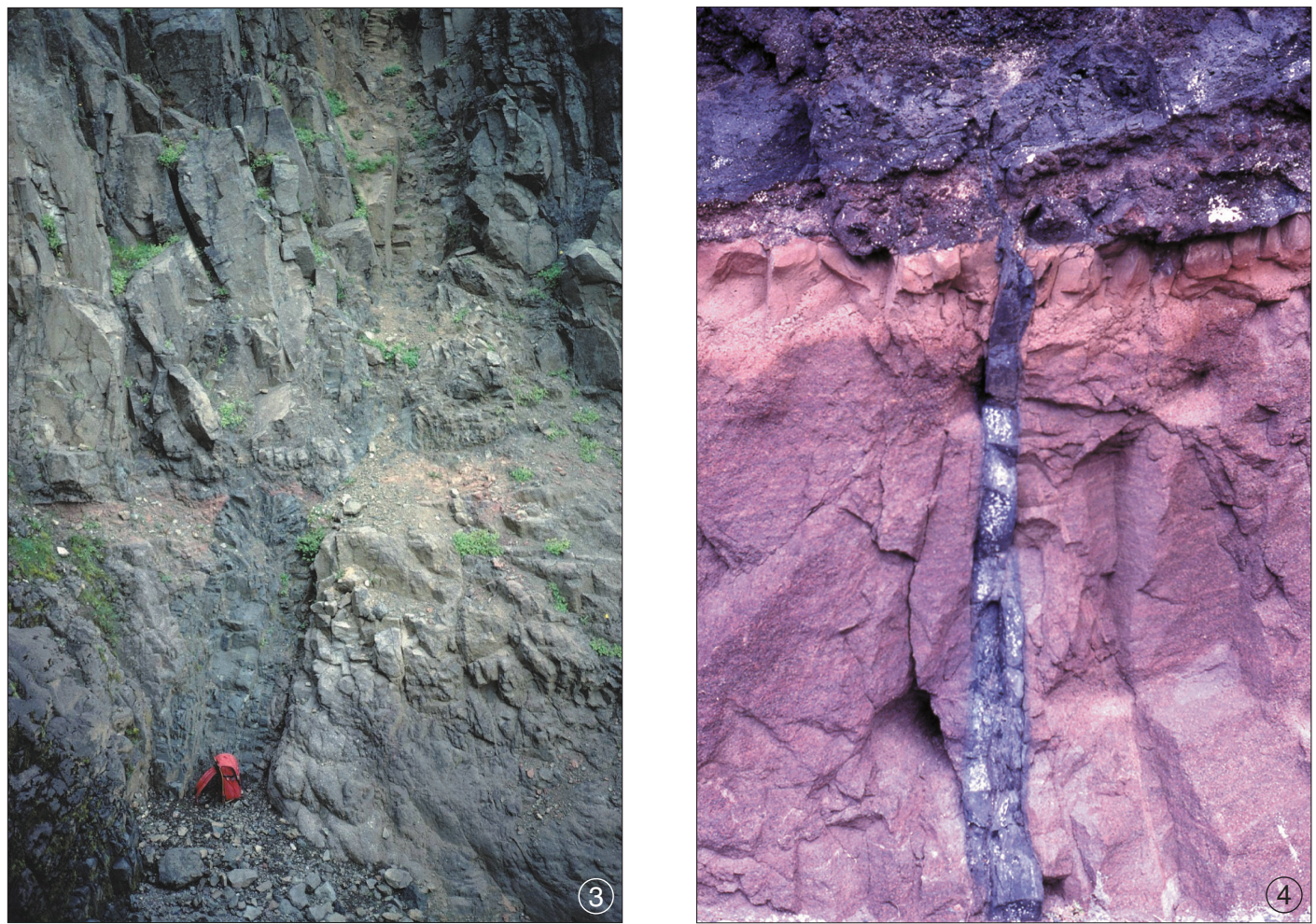

Fig. 3. Dyke becomes offset on crossing a weak scoria contact between two basaltic lava flows, of Tertiary age, in the palaeorift zone of North Iceland. View north, the dyke is around $1 \mathrm{~m}$ thick; the backpack at the lower dyke segment provides a scale.

Fig. 4. Arrested tip of a basaltic dyke in a vertical exposure in the lava pile of Tenerife (Canary Islands). The dyke exposure is $3.7 \mathrm{~m}$ tall, strikes E-W, and dissects a baked pyroclastic rock layer in the lower part of the photograph. The dyke is $0.26 \mathrm{~m}$ thick near the bottom of the exposure (at a road), and its thickness is similar up to near the contact between the pyroclastic rock and the basaltic lava flow (on top). There the dyke abruptly tapers away towards its tip. No dyke-induced joints or faults occur at the dyke tip. 


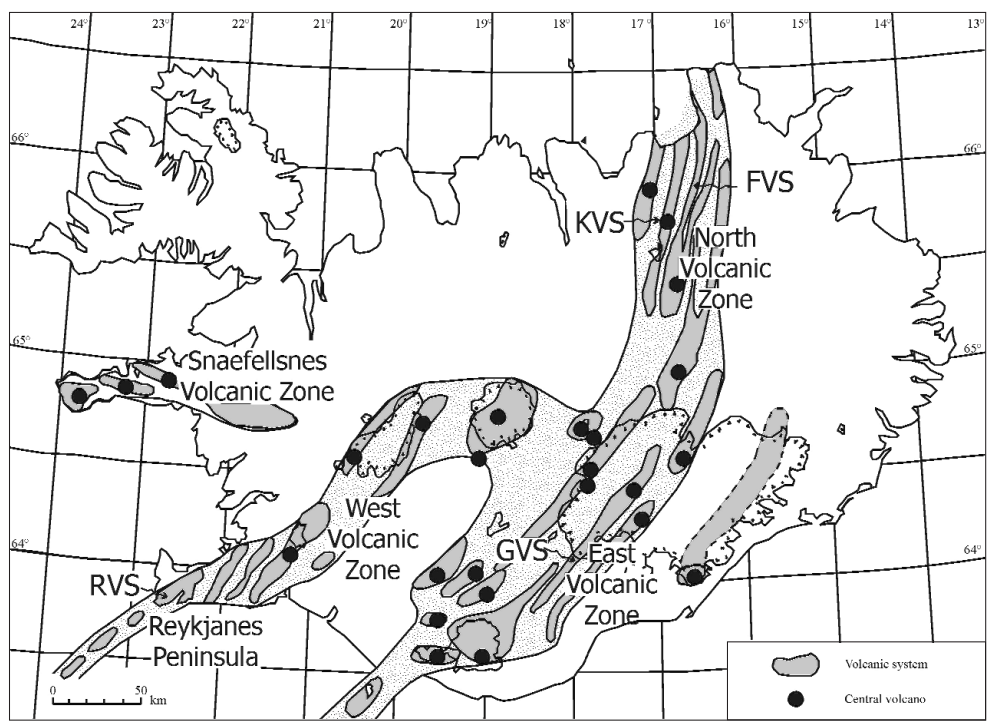

Fig. 5. The active volcanic zones of Iceland consist of volcanic systems most of which have associated central volcanoes (stratovolcanoes). The main volcanic zones are the North Volcanic Zone, the East Volcanic Zone and the West Volcanic Zone. The active rift zone comprises all these zones except for the southernmost part of the East Volcanic Zone which is a propagating rift ( $c f$. Gudmundsson, 2000). FVZ stands for the Fremrinamur Volcanic System, KVS for the Krafla Volcanic System, GVS for the Grimsvotn Volcanic System, and RVS for the Reykjanes Volcanic System.

fices and rift zones. These data indicate that mechanical, rather than thermal, conditions are of primary importance in controlling the arrest of dykes or, alternatively, their propagation to the surface as feeder dykes. These mechanical conditions are reflected in the local stress fields associated with individual layers and contacts in the volcanic edifices. When a dyke meets with a contact between rock layers of contrasting mechanical properties, it is the local stress field associated with these layers that controls whether or not the dyke propagates through the contact (with or without an offset) or, alternatively, becomes arrested (Gudmundsson, 2002; Gudmundsson et al., 2002).

Many authors have suggested that a dyke arrested at a considerable depth below the surface of a volcanic edifice or a rift zone during a period of unrest may contribute to brittle deformation of the surface (e.g., Pollard and Holzhausen, 1979; Okada, 1985; Rubin and Pollard, 1988). Most models used to inverse surface data to infer dyke geometries assume that the host rock may be modelled as a homogeneous, isotropic half space and imply that the host-rock stresses are uniform. Although the use of homogeneous, isotropic half-space models for analysing ground deformation in volcanoes has been criticised (e.g., De Natale and Pingue, 1993), they continue to be routinely used, presumably because they are simple (e.g., Jousset et al., 2003), to help assess volcanic hazards during periods of unrest.

Some of the homogeneous, isotropic halfspace models predict that stresses associated with arrested dykes may induce major grabens at rift-zone and edifice surfaces (Pollard and Holz-hausen, 1979). Many tens of arrested dyke tips have been observed in eroded rift zones, however, and few, if any, of these are associated with grabens or normal faults that could be generated by dyke-induced stresses ahead of the tips (Gudmundsson, 2002, 2003). Also, normal faults and grabens tend to be more common in those parts of eroded rift zones 
where dykes are relatively rare, and there are dykes arrested within a few metres of the surface that do not generate faults or grabens at the surface (Gudmundsson, 2003).

In this paper the focus is on the effects of local stress fields on dyke propagation, dyke arrest, and the surface deformation associated with arrested dykes in rift zones and volcanic edifices. The first part of the paper reviews the results of field observations of several thousand dykes, primarily in Iceland (fig. 5) and Tenerife (Canary Islands), focusing on feeder dykes, ar-

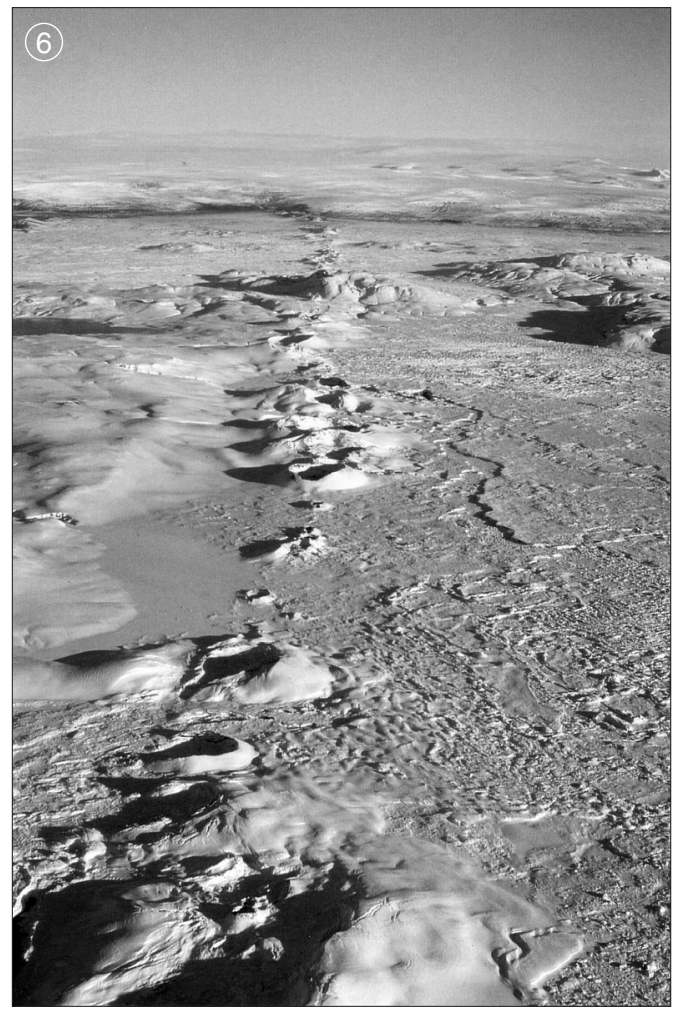

rested dyke tips, and associated dyke tips and surface deformations. The second part of the paper presents analytical and numerical models as to how local stress fields in layered rocks affect dyke propagation, dyke arrest and surface deformation in rift zones and volcanic edifices.

\section{Feeder dykes}

For a volcanic eruption to occur, it is normally necessary that a magma chamber be-

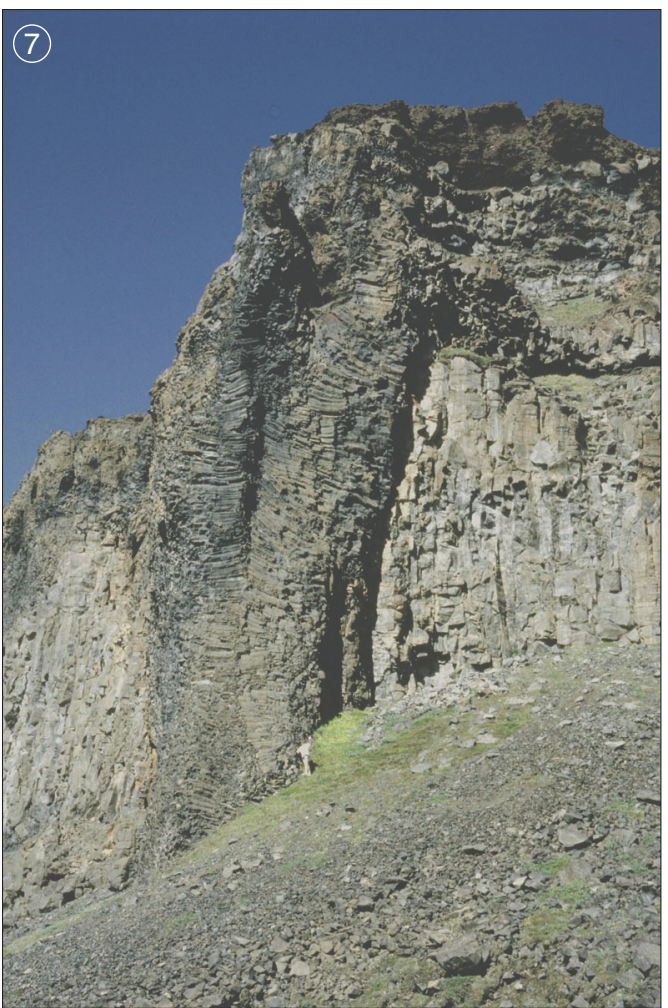

Fig. 6. Part of a volcanic fissure with crater cones in the Grimsvotn Volcanic System of the East Volcanic Zone (fig. 5). View northeast, this crater row, which has a total length of $27 \mathrm{~km}$ (Thordarson and Self, 1993), was formed during the Laki 1783 eruption, the largest historical eruption in Iceland.

Fig. 7. On solidification, subvertical magma-driven fractures that reach the surface become feeder dykes, like this 6000-8000-year-old feeder dyke in the canyon of the river Jokulsa a Fjollum, at the eastern margin of Fremrinamur Volcanic System of the active rift zone in North Iceland (fig. 5). The dyke is around $6 \mathrm{~m}$ thick where the person is standing, but gradually increases in thickness to around $10 \mathrm{~m}$ where it meets the free surface at the time of eruption and connects with a crater cone (cf. Gudmundsson, 1995). 
comes ruptured and a magma-filled fracture forms. But this condition is not sufficient. An additional condition is that the magma-filled fracture must be able to propagate to the surface, through all the many local stress fields that affect its potential pathway. When the magmafilled fracture reaches the surface, it forms a volcanic fissure (fig. 6), an opening-mode fracture (mode I crack) that subsequently develops crater cones and is then referred to as a crater row.

On solidification, the magma-filled fractures that feed crater rows become feeder dykes. One of the best-exposed feeder dykes in Iceland is the one that supplied magma to the 50-70 km long Sveinar-Randarholar crater row in Northeast Iceland (fig. 7). This 6000-8000-year-old feeder dyke is best exposed in the east walls of a $100 \mathrm{~m}$ deep canyon of a glacial river where it cuts through the Holocene volcanic rift zone in Northeast Iceland. The dyke is in a visible connection with one of the crater cones of the crater row, where it reaches a thickness of around $10 \mathrm{~m}$, but thins to 5-7 $\mathrm{m}$ in the deeper parts of the exposure. The greater thickness (opening) of the volcanic fissure where it dissects the palaeosurface of the rift zone (on which the crater cone rests) is due to the free-surface effects on the opening-displacement of the fracture (Tada et al., 2000).

Several other feeder dykes are known from Iceland. Most of them, however, are located inside the active volcanic zones, such as the one in fig. 7. Generally, surprisingly few well-documented feeder dykes have been reported from active and extinct volcanic areas, indicating that much more work is needed in this field of volcanology. By contrast, many arrested dykes have been described. The main features of typical arrested dyke tips are summarised in the next section.

\section{Arrested and offset dykes}

As an example of a dyke arrested at the contact between layers of contrasting mechanical properties, we consider the dyke in fig. 4. This is an E-W striking basaltic dyke that cuts through a layer of pyroclastic rock in lower part of the exposure. At the bottom of the 3.7-m-tall exposure, the dyke is $0.26 \mathrm{~m}$ thick, and maintains roughly that thickness up to the contact be- tween the pyroclastic rock and the basaltic lava flow at the surface. At the contact, the dyke thins abruptly and ends vertically in the scoracious bottom of the basaltic lava flow. As is common in such situations, the dyke may continue as an offset segment higher up in the lava pile. However, there are no visible igneous veins or other connections between the segment seen to end vertically in fig. 4 and dyke segments at shallower levels in the pile exposed in this section.

Another example of an arrested dyke occurs in well-exposed cliffs where the Holo- cene rift zone of Southwest Iceland enters into the sea (fig. 8). At the bottom of the $8 \mathrm{~m}$-tall exposure, the dyke thickness is $0.34 \mathrm{~m}$ but decreases on approaching the contact between the pyroclastic rock and the Holocene basaltic lava flow above. This lava flow, referred to as Yngri Stampar, was erupted between 1210-1240 A.D. (Sigurgeirsson, 1995), so that the dyke must be of around this age or younger. The dyke tip, which is rounded, is arrested at the contact. Although the tip is arrested at only $5 \mathrm{~m}$ below the surface of the Holocene rift zone, there is no visible faulting or graben formation in the lava flow between the tip and the surface.

Some of the many typical ends of arrested dykes are indicated in fig. 9a-d. These are based on field studies of around 14-Ma-old basaltic dykes in the Tertiary lava pile in Northwest Iceland. In thick, comparatively homogeneous and isotropic lava flows most dykes end vertically by tapering away (fig. 9a). Similar dyke tips are observed, both in lava flows and in thick pyroclastic layers, in Tenerife (Marinoni and Gudmundsson, 2000). Although many dykes become arrested on meeting with subhorizontal contacts (figs. 4 and 8), some become arrested on meeting with inclined fractures (fig. 9b). It is common to see the dyke tip expanding on meeting with a soft layer, particularly scoria layers at the bottom of stiff lava flows, in which case the dyke may be offset across the contact (fig. 3). Many offset dykes try several pathways, sending off thin, igneous veins, before selecting the eventual pathway. Other dykes expand on meeting with stiff lava flows (which may also have comparatively high tensile strengths) and propagate partly into the bottoms of the lava flows, but fail to propagate through the lavas and so become arrested (fig. 9c,d). 


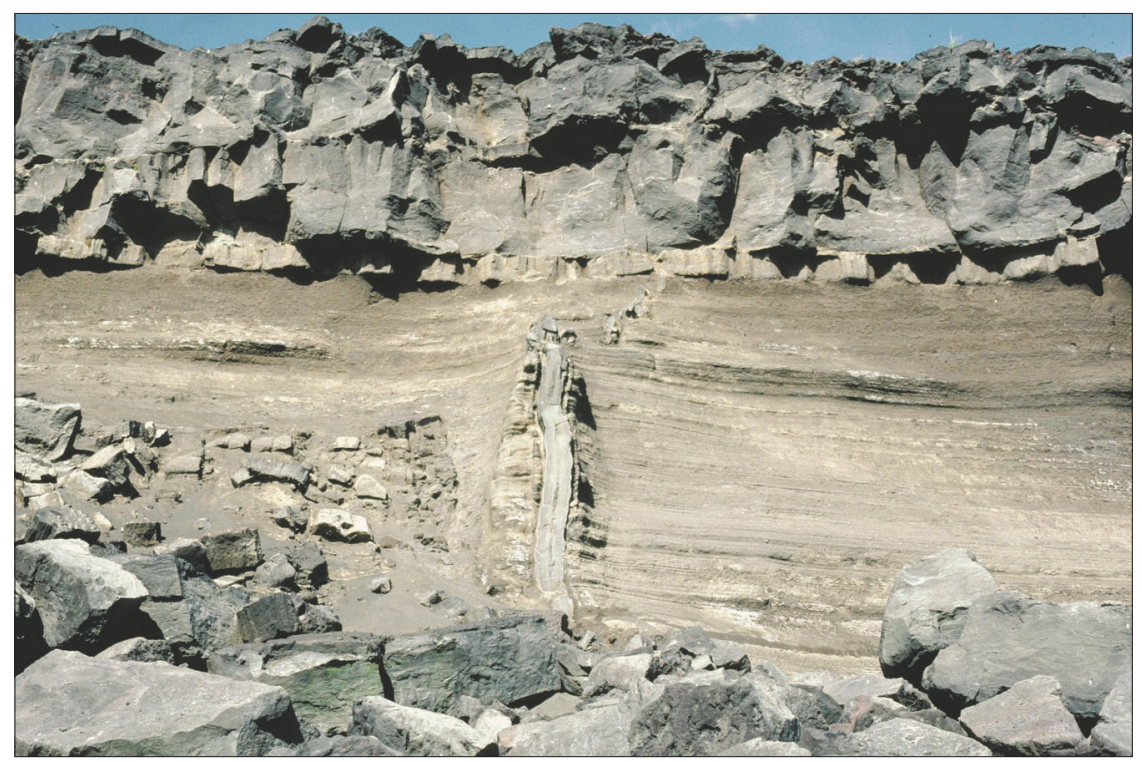

(8)

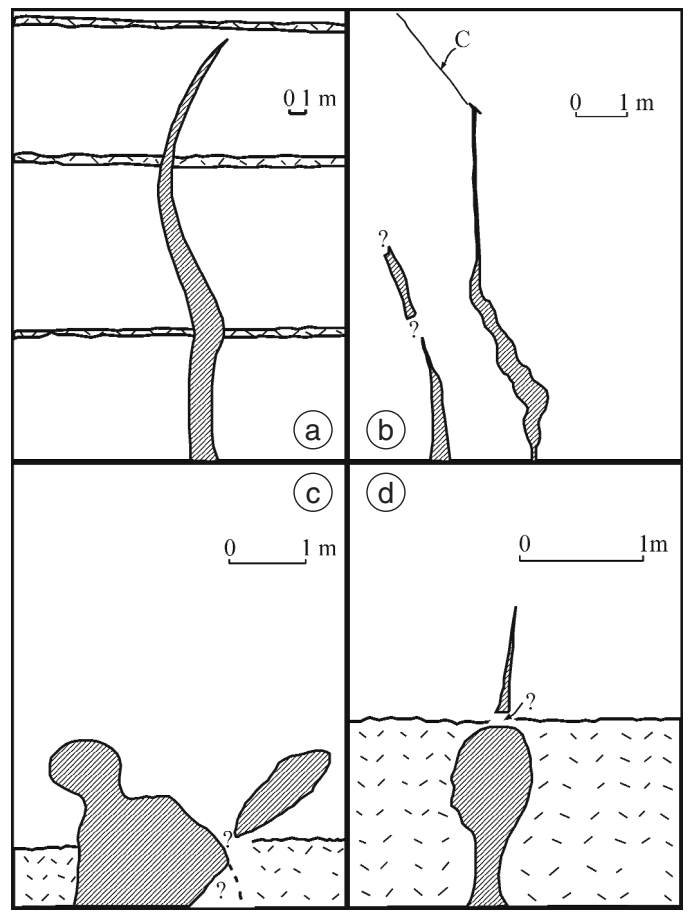

(9)
Fig. 8. Arrested dyke tip exposed in sea cliffs that cut through the Reykjanes Volcanic System in the Holocene rift zone of Southwest Iceland (fig. 5). This basaltic dyke strikes northeast, is subvertical, and cuts through a layer of pyroclastic rock (volcanic tuff) in the lower part of the photograph. The dyke tip is arrested at the contact between the pyroclastic rock and the Holocene basaltic lava flow that forms the surface of the rift zone. The dyke thickness is from $0.34 \mathrm{~m}$, at the bottom of the $8 \mathrm{~m}$ tall exposure, to $0.1 \mathrm{~m}$ at the tip. There are no dyke-induced fractures or normal faults above the dyke tip.

Fig. 9a-d. Four arrested dykes in the (14 Ma) basaltic lava pile of Northwest Iceland. In this schematic illustration, the dykes are shaded, the scoria layers between the lava flows are hatched, and the basaltic lava flows themselves are not shaded. The dykes occur in outcrops which are steep to vertical cliffs; the indicated scale is approximate. In (a) the dyke tapers away in the lava pile, in (b) the dyke tip is arrested at an oblique fracture (indicated by c) in a thick lava flow, in (c) the dyke has propagated for a short vertical distance into the bottom of the lava flow and expanded its arrested tip (cf. fig. 3), and in (d) the dyke sends off a thin, vertical igneous vein into the bottom of a massive lava flow but otherwise expands and becomes arrested at the contact between the soft scoria layer and the stiff basaltic lava flow (cf. fig. 3). 
Dyke offsets across layers of contrasting mechanical properties, such as illustrated in fig. 3 , are very common. Some dyke segments are connected by thin, igneous veins across the contacts (fig. 10), in which case there is no doubt that the segments belong to the same dyke. Other dyke segments, however, have no visible connections; a feature that is particularly common in lateral sections (Gudmundsson, 1995).

A remarkable feature of some offset dykes (and sheets) is that they are continuous across the contact between two layers (lava flows), but a part of the dyke follows the subhorizontal contact for a while (fig. 11). Examples are known from Iceland where a dyke changes into a sill at a contact between layers, follows the contact for many metres and then continues its vertical propagation up into the lava pile.

These results indicate that contacts between layers of contrasting mechanical properties have commonly strong effects on dyke propagation. These effects are partly related to the mechanical weakness of the contact itself, which may open up

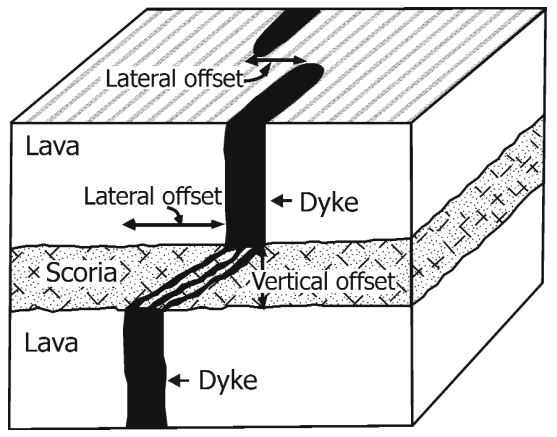

Fig. 10. When dykes dissect contacts between lava flows, particularly scoria layers that are still weak when the dyke injection occurs, they commonly become laterally and vertically offset (cf. fig. 3). Some dyke segments, however, are connected by thin igneous sheets, like here. Lateral dyke offsets are also very common, both in eroded, extinct dyke swarms, like here, as well as at the surfaces of active rift zones and volcanic edifices, where the feeder dykes are seen as volcanic fissures. For example, the Laki Volcanic Fissure, part of which is seen in fig. 6, is offset in many places ( $c f$. Thordarson and Self, 1993).

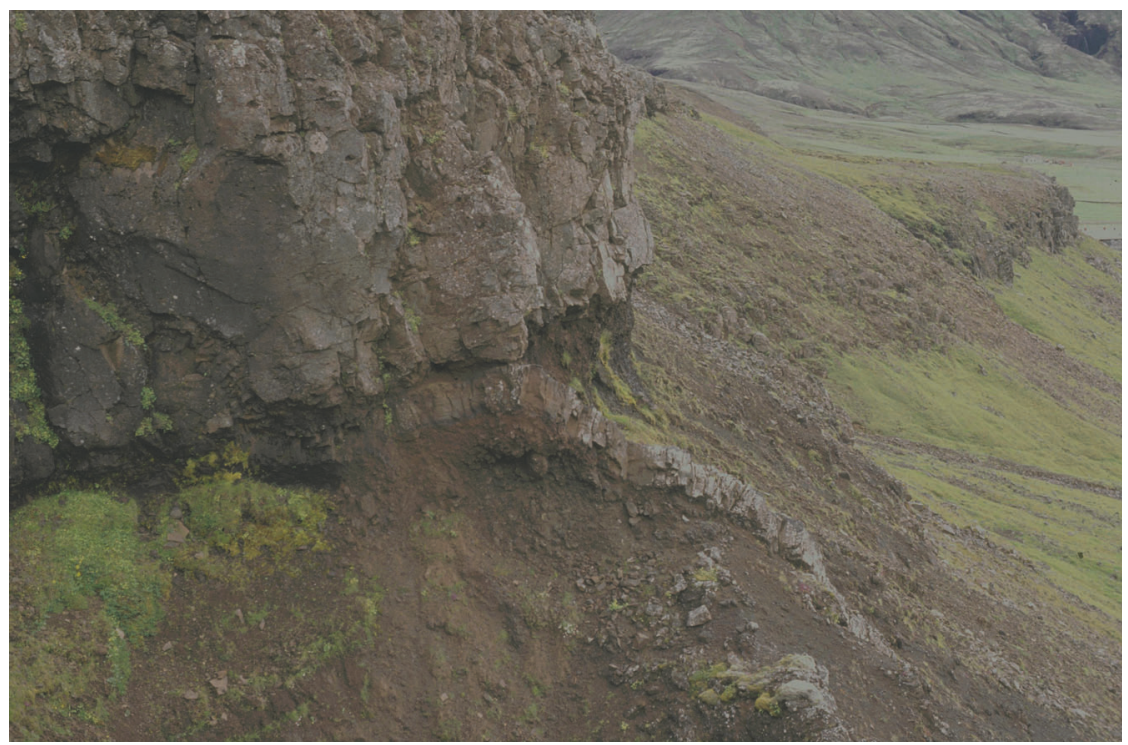

Fig. 11. Inclined, 0.5-1 $\mathrm{m}$ thick sheet in the Pleistocene lava pile in Southwest Iceland. The contact between the weak scoria (below) and the basaltic lava flow (on the top) has opened up, so as to allow the sheet to follow it for several metres until the sheet continues its inclined propagation up through the lava flow on the top. Opening of weak contacts when magma-filled fractures approach them is a common feature, as is modelled in fig. 20. 
when the dyke tip approaches. The dyke may follow the contact as a sill for a while or end altogether when meeting with the contact (Gudmundsson et al., 2002). Partly, however, these effects have to do with local stresses which may develop at, and in the vicinity of, contacts between rock layers of contrasting mechanical properties. These stress fields are often unfavourable to dyke propagation and may encourage dyke arrest.

\section{Stress fields favouring dyke arrest}

Most dykes never reach the surface to supply magma to volcanic eruptions, but rather become arrested. This conclusion is based on theoretical considerations (Gudmundsson, 2002) and is supported by many field studies. For example, in dyke profiles in Iceland and Tenerife arrested dykes are much more common than feeder dykes (Marinoni and Gudmundsson, 2000; Gudmundsson, 2002). Similar results are obtained from ophiolites and dyke swarms exposed in the walls of large fracture zones (Pallister, 1981; Pedersen, 1986; Dilek et al., 1998; Karson, 1998). Also, estimates of the magma balance in active volcanoes indicate that the volume of intruded magma greatly exceeds that of erupted magma. For instance, the estimated ratio of erupted to intruded volumes of magma in the Krafla Central Volcano in North Iceland (fig. 5) for the period 1975-1984 is 0.30 , whereas that for Etna for the period 19801995 is 0.13 (Harris et al., 2000).

On a regional scale, the general decrease in stiffness (Young's modulus) of the crust as the surface of a volcanic rift zone is approached (Palmason, 1971) indicates that most dykes injected from magma reservoirs become arrested on their way to the surface (Gudmundsson, 2002). As regards individual volcanic edifices and parts of volcanic rift zones, however, the arrest of dykes can be mostly explained in terms of two related factors: stress barriers and mechanical anisotropy. As used here, a stress barrier is any layer with a local stress field that is unfavourable to dyke propagation, whereas a mechanical anisotropy covers discontinuities such as joints and weak or open contacts that may arrest dykes.
More generally, the term stress barrier includes any rock body where the stress field is unfavourable to the type of fracture propagation under consideration, whether the fractures are shear fractures (faults), such as in earthquakes, or hydrofractures, such as mineral-filled veins, inclined sheets, sills or dykes (Gudmundsson, 2002). Here the term stress barrier is used in the restricted sense of a rock layer with a stress field unsuitable for dyke propagation, and thus encouraging dyke arrest. For vertical dyke propagation, a stress barrier is thus a layer with a locally high horizontal compressive stress.

Stress barriers may develop in many ways. One is the gradual decrease in stiffness with altitude in rift zones. Another is the fall off in intensity of the (relative or absolute) tensile stresses generated around a pressured magma chamber with increasing distance from that chamber. Then dyke injection is favoured in the vicinity of the chamber while at a certain distance from the chamber the stress field favours dyke arrest. The third way for stress barriers to form is when rock layers of contrasting mechanical properties meet. Depending on the loading conditions, either the soft layers (during extension) or the stiff layers (during compression) may then act as stress barriers ( $c f$. Gudmundsson and Brenner, 2001).

\subsection{Homogeneous, isotropic crust}

Many magma chambers, particularly in the later stages of their development, approach the geometries of spheres and cylinders (Gudmundsson, 2002). We shall here consider the analytical solutions for the stress fields around ideal spherical and cylindrical magma chambers to illustrate how dyke injection may be favoured in the vicinity of the chambers while dyke arrest is encouraged at greater distances from the chambers.

Consider first a spherical magma chamber with radius $R_{1}$. To simplify the problem, we consider the chamber to be deep-seated and located within a larger rock sphere, of radius $R_{2}$, where $R_{2} \gg R_{1}$. Geologically, this means that the chamber radius is small in comparison with its depth below the free surface of the associat- 
ed volcanic edifice. The chamber ruptures and initiates a dyke or and inclined sheet, depending on the stress situation and location of rupture (Gudmundsson, 1998), when the following conditions are satisfied:

$$
P_{t}=\sigma_{3}+T_{0}
$$

or

$$
p_{l}+p_{e}=\sigma_{3}+T_{0} .
$$

In this notation, $p_{e}=P_{t}-p_{l}$, is the excess magmatic pressure in the chamber, that is, the difference between the total magma pressure, $P_{t}$, at the time of chamber rupture and the lithostatic stress $p_{l}$. Field observations indicate that dykes and sheets are mostly extension fractures (Gudmundsson, 1995), meaning that they form in planes that are perpendicular to the local minimum principal compressive (maximum tensile) stress $\sigma_{3}$. For a dyke injection to occur, the excess pressure, $p_{e}$, in the chamber must reach the local in situ tensile strength, $T_{0}$, of the chamber walls at the rupture sites. Following the convention in structural geology and rock mechanics, compressive stress is considered positive and tensile stress negative. However, in many of the applications in this paper, we take the symbols to represent absolute values, in which case the minus signs can be omitted.

Consider a chamber subject to a total magma pressure $P_{t}$ at its boundary $R_{1}$ while there is lithostatic stress $p_{l}$ at the outer radius $R_{2}$ of the spherical elastic body within which the chamber is located (in reality, a crustal segment). Using the total magma pressure $P_{t}$ as defined in eq. (4.1), the radial stress $\sigma_{r}$ is given by (Saada, 1983)

$$
\sigma_{r}=P_{t}\left(\frac{R_{1}}{r}\right)^{3}+p_{l}\left[1-\left(\frac{R_{1}}{r}\right)^{3}\right]
$$

Similar equations can be presented for the tensile stresses $\sigma_{\theta}$ and $\sigma_{\phi}$ (Saada, 1983; Gudmundsson, 2002). For these stresses, the spherical polar coordinates $(r, \theta, \phi)$ are used, $r$ being the radius vector, $\theta$ the angle between the radius vector and a fixed axis, and $\phi$ the angle measured around this axis.
A simpler presentation of eq. (4.3), and the related equations for $\sigma_{\theta}$ and $\sigma_{\phi}$, can be obtained if the excess magma pressure $p_{e}$, as defined in eq. (4.2), is used instead of the total pressure $P_{t}$. Then eq. (4.3) reduces to

$$
\sigma_{r}=p_{e}\left(\frac{R_{I}}{r}\right)^{3}
$$

and the equation for the tensile stresses $\sigma_{\theta}$ and $\sigma_{\phi}$ (which are equal because of spherical symmetry) becomes

$$
\sigma_{\theta}=\sigma_{\phi}=-\frac{p_{e}}{2}\left(\frac{R_{1}}{r}\right)^{3} .
$$

Equations (4.4) and (4.5) show that the intensity of the stress field associated with a deepseated spherical magma chamber falls off inversely as the cube of the distance $r$ from the chamber (fig. 12).

Similar results are obtained in case the magma chamber is modelled as a vertical cylinder. Such a model is appropriate, for example, for magma chambers that, on solidification, become plugs or necks (if small) or stocks (if large). Many volcanic edifices, particularly those that develop swarms of radial dykes, are likely to have cylindrical magma chambers. Consider a cylindrical chamber of radius $R_{1}$ located in a cylindrical rock body of radius $R_{2}$, where $R_{2}>R_{1}$. Geologically, the solid cylindrical rock body is just that part of the crust surrounding the cylindrical magma chamber which is of interest in the problem. As in the case of a spherical magma chamber, the rock body hosting the chamber is, for mathematical convenience, assumed to have the same shape as the chamber.

Using polar coordinates, with radius vector $r$ and polar angle $\theta$, we next consider a cylindrical magma chamber subject to a total magma pressure $P_{t}$, as defined in eq. (4.1), at its radius, $R_{1}$. The cylindrical rock body hosting the chamber is subject to an external total horizontal compressive stress $\sigma_{H}$ at $R_{2}$. The state of stress in the host rock is taken to be isotropic so that the maximum, $\sigma_{H}$, and minimum, $\sigma_{H}$, horizontal compressive stresses are equal. The radial stress $\sigma_{r}$ away from the 

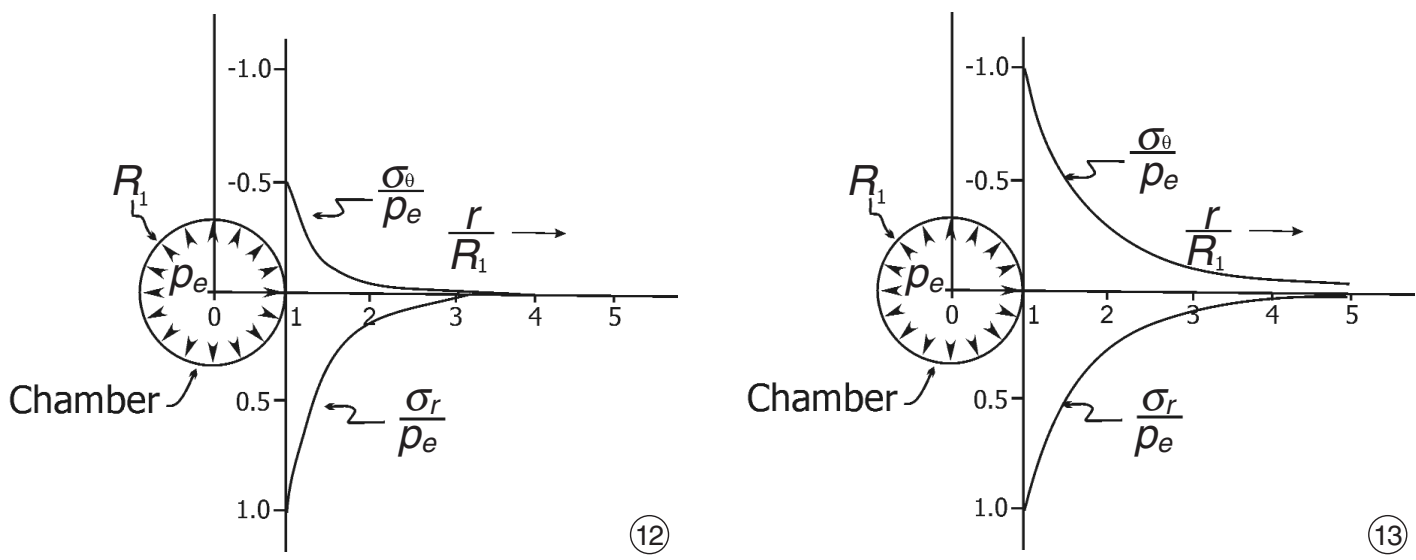

Fig. 12. Decrease in intensity (magnitude) of the tensile circumferential stress $\sigma_{\theta}$ and the compressive radial stress $\sigma_{r}$ with increasing distance from the margin of a spherical magma chamber subject to an excess magmatic pressure $p_{e}$. The variation is seen in a vertical plane. The stresses are made dimensionless through dividing by the magmatic excess pressure and the distance is made dimensionless by dividing the radius vector $r$ (distance) by the radius of the magma chamber $R_{1}$.

Fig. 13. Decrease in intensity (magnitude) of the tensile circumferential stress $\sigma_{\theta}$ and the compressive radial stress $\sigma_{r}$ with increasing distance from the margin of a (vertical) cylindrical magma chamber subject to an excess magmatic pressure $p_{e}$. The variation is seen in a horizontal plane. The stresses are made dimensionless through dividing by the magmatic excess pressure and the distance is made dimensionless by dividing the radius vector $r$ (distance) by the radius of the magma chamber $R_{1}$.

chamber can then be obtained from the equation (Saada, 1983)

$$
\sigma_{r}=P_{t}\left(\frac{R_{1}}{r}\right)^{2}+\sigma_{H}\left[1-\left(\frac{R_{1}}{r}\right)^{2}\right] .
$$

As in the case of the spherical magma chamber, a simpler presentation of eq. (4.6), and the related equation for the tangential or circumferential stress $\sigma_{\theta}$, can be obtained if one substitutes the excess magma pressure $p_{e}$ for the total magma pressure $P_{t}$. Then $\sigma_{H}$ is taken to be equal to the lithostatic stress in the crust outside the chamber, so that $\sigma_{H}=\sigma_{h}=p_{l}$. Then eq. (4.6) reduces to

$$
\sigma_{r}=P_{e}\left(\frac{R_{1}}{r}\right)^{2}
$$

Similarly, the circumferential stress is given by (Gudmundsson, 2002)

$$
\sigma_{\theta}=-P_{e}\left(\frac{R_{1}}{r}\right)^{2}
$$

Equations (4.7) and (4.8) show that, for a vertical cylindrical magma chamber, the intensity of the stress field generated by the excess pressure $p_{e}$ falls off with the square of the distance $r$ from the chamber (fig. 13).

From eqs. (4.1) and (4.2) it follows that the excess pressure $p_{e}$ in a chamber at the time of rupture and dyke injection is normally equal to the local tensile strength, that is, $p_{e}=T_{0}$. In situ tensile strengths of most rocks are low, the typical values being 0.5-6 MPa (Haimson and Rummel, 1982; Schultz, 1995; Amadei and Stephansson, 1997). It follows that, at chamber rupture and initiation of a dyke or an inclined sheet, the tensile stresses at the margin of the chamber are small and diminish rapidly with increasing distance along the potential pathway of the propagating dyke.

Consequently, in host rocks that can be modelled as homogeneous and isotropic, the stress 
fields associated with ideal spherical and cylindrical magma chambers may commonly satisfy the conditions for dyke injection and propagation in the vicinity of the chambers while at certain limited distances from the chambers satisfy the conditions for dyke arrest. Many dykes may thus propagate for only a short distance from the source chamber until they enter a stress barrier in which they become arrested.

\subsection{Layered crust with a gradual increase in stiffness with depth}

Although the variation in layer stiffness is likely to be irregular in rift zones and volcanic edifices, seismic studies generally indicate an average increase in stiffness with increasing crustal depths (Palmason, 1971). Here we use these results, together with analytical and numerical models, to show that this increase in stiffness with depth favours dyke arrest at shallow depths.

We consider flat, sill-like, elongated magma reservoirs, such as presumably underlie large parts of the rift-zone volcanic systems in Iceland (Gudmundsson, 2000). The conditions of rupture and dyke injection (eqs. (4.1) and (4.2)) are presumably commonly reached through reduction in $\sigma_{3}$ in the roof of a reservoir as a consequence of buildup of relative or absolute tensile stress generated by plate movements (plate pull). The buildup of tensile stress can be inferred from the one-dimensional Hooke's law in elasticity which relates tensile stress $\sigma$ and strain $\varepsilon$ through the equation (Timoshenko and Goodier, 1970)

$$
\sigma=E \varepsilon
$$

where $E$ is the stiffness (Young's modulus) of the crust. In the convention used in this paper, both the tensile stress and strain should be negative, but to simplify the discussion they are here considered as absolute values and the minus signs are dropped.

The part of a rift zone that undergoes tensile strain during plate movements (plate pull) corresponds closely to the width $u$ of the associated volcanic system(s) (figs. 5 and 14). If the associated spreading rate is denoted by $v$ (fig. 14), the buildup rate of tensile stress $d \sigma / d t$ in the rift zone (when there is no shape-related stress concentration in the roof of the sill-like magma reservoir) is

$$
\frac{d \sigma}{d t}=\frac{v E}{u} .
$$

The rate $d \sigma / d t$ has the units of $1 / \mathrm{yr}$, and the time $t_{i}$ for the tensile stress in the crust to reach its tensile strength $T_{0}$ is

$$
t_{i}=\frac{T_{0}}{d \sigma / d t}=\frac{u T_{0}}{v E} .
$$

Although eq. (4.11) applies in the case of a silllike magma reservoir where there is no tensile stress concentration in the chamber roof, the results can easily be extended to magma reservoirs of different shapes where there will be stress concentration in the reservoir roof (Gudmundsson, 1998). Here, however, the focus is on sill-like reservoirs.

The dyke-injection frequency associated with the magma reservoir, $i_{f}$, is the reciprocal of $t_{i}$, and is, from eq. (4.11), given by

$$
i_{f}=\frac{1}{t_{i}}=\frac{v E}{u T_{0}} .
$$

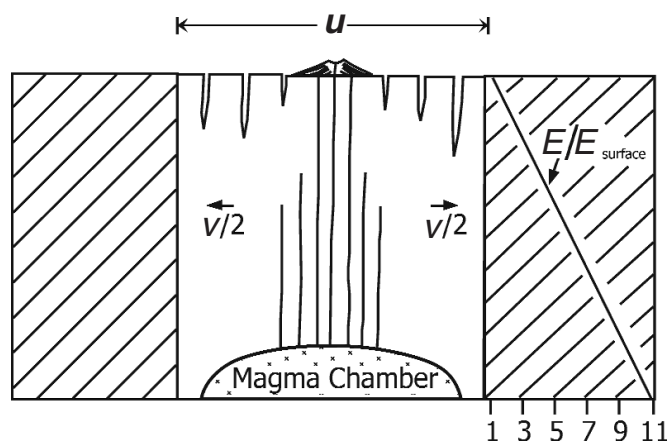

Fig. 14. The part of a rift zone that is subject to tensile strain during plate movements (plate pull) with a total spreading (opening) rate of $v$ (half rate $v / 2$ ) has the width $u$ ( $c f$. Gudmundsson, 1990). In this model, the crustal stiffness (Young's modulus, $E$ ) increases linearly with depth; the surface modulus being $E_{\text {surface }}$. 
Equation (4.12) applies to a single magma reservoir and, in particular, to a deep-seated magma reservoir such as may exist beneath most of the rift-zone volcanic systems in Iceland (Gudmundsson, 1995). These reservoirs normally feed the eruptions in the rift-zone volcanic systems outside volcanic edifices, that is, outside stratovolcanoes or central volcanoes (fig. 5).

Using the simple model of a general increase in stiffness with increasing crustal depth, the above equations can be applied to the dyke-injection frequency in a rift zone outside its central volcanoes (fig. 5) and compared with those obtained from extinct volcanic systems in Iceland. Extinct volcanic systems are represented by a typical dyke swarm in the Tertiary lava pile of East Iceland (fig. 15), for which the width of the source reservoir may be taken as $10 \mathrm{~km}$ (Gudmundsson, 1995).

In the Tertiary, as in South Iceland today (fig. 5 ), the rift zone was split in two parts, each one taking up roughly half the spreading rate. Because, in addition, many of the dyke swarms are parallel, or overlap to a large degree (fig. 5), the spreading rate of a single swarm is of the order of $0.5 \mathrm{~cm} \mathrm{yr}^{-1}$, that is, around one-fourth of the total spreading (opening) rate in Iceland (Gudmundsson, 2000). The roof of the reservoir is taken to be located in a host rock with a static stiffness (Young's modulus) of $E=67 \mathrm{GPa}$ (Gudmundsson, 1990). In the model of Staples et al. (1997), this stiffness implies that the reservoir is located in the lowermost part of the crust, but in Palmason's (1971) model the reservoir is located at the boundary between the crust and upper mantle. With a typical in situ tensile strength of $T_{0}=3$ $\mathrm{MPa}$, eq. (4.12) yields the dyke-injection frequency $i_{f} \approx 0.01 \mathrm{yr}^{-1}$, meaning that one dyke is injected from the reservoir every 100 years.

These theoretical results can be compared with the number of dykes observed in a typical Tertiary dyke swarm in Iceland such as the Alftafjördur Dyke Swarm in East Iceland (fig. 15; Gudmundsson, 1995). The dykes in this swarm are mostly exposed at crustal depths of $0.5-1.3 \mathrm{~km}$ below the initial top of the lava pile, which has been eroded by the glaciers of the Ice Age. At this crustal depth, the estimated static stiffness is around $10 \mathrm{GPa}$ (Gudmundsson, 1990 ), or about $15 \%$ of the stiffness of the roof of the reservoir $(67 \mathrm{GPa})$ used in the above cal-

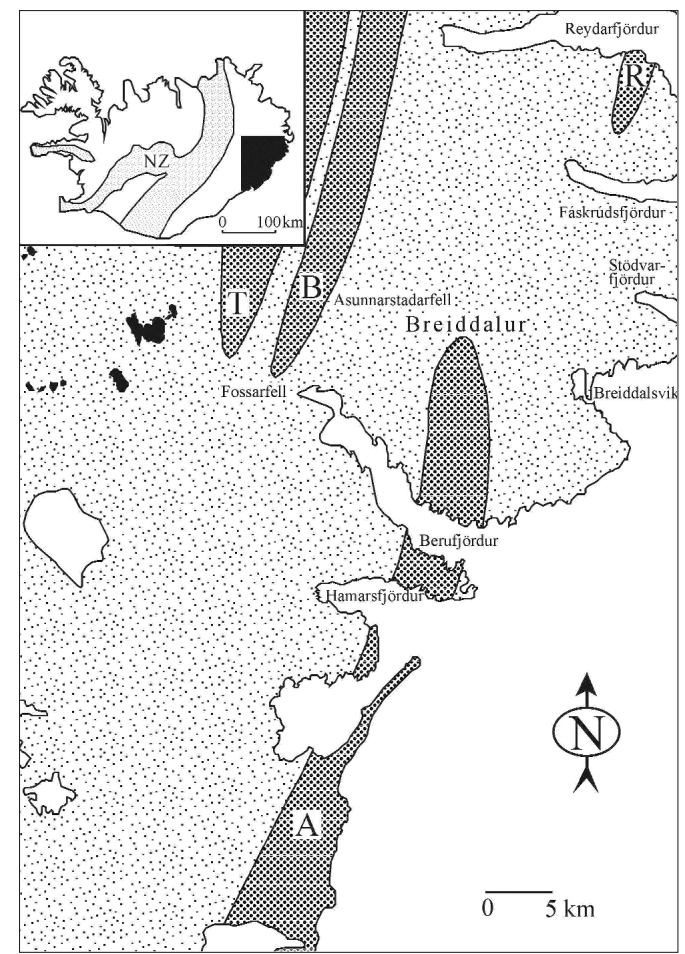

Fig. 15. Dyke swarms and associated central volcanoes (stratovolcanoes, edifices) in East Iceland. The main dyke swarms and central volcanoes indicated are Alftafjordur (A), Breiddalur (B), Reydarfjordur (R), and Thingmuli (T), (cf. Walker, 1963 and Gudmundsson, 1995).

culations. From eqs. (4.9) and (4.12) we can thus infer that only $15 \%$ of the dykes injected from the magma reservoir reach this crustal level. It follows that during a typical lifetime of a volcanic system (and its associated source reservoir) of 0.3-1 Ma (Gudmundsson, 2000), between 450 and 1500 dykes should occur in the Alftafjördur Swarm at the present exposure. This is in good agreement with the estimated total number of exposed dykes in the Alftafjördur Swarm, 1000 to 1500 dykes (Gudmundsson, 1995). Thus, the gradual increase in stiffness with crustal depth (Gudmundsson, 1990) may be a good first-approximation explanation for the number of regional dykes found at a particular crustal depth in an extinct volcanic system. 


\subsection{Layered crust with abrupt stiffness changes with depth}

Next we consider a shallow chamber in a layered crust and ignore the stress effects of the deep-seated source reservoir. This we do because the focus is here on the stresses in the crust above the shallow chamber where the stress-effects of the deeper reservoir are negligible. For this purpose, we made several boundary-element models, using the BEASY (1991) program, of a magma chamber with a circular cross section in a layered crust where the layer stiffness increases gradually with depth (fig. 16). The boundary-element method in general, and the BEASY program in particular, are described by Brebbia and Dominguez (1992), the BEASY homepage (www.beasy.com), BEASY (1991), and Jing and Hudson (2002).

The model in fig. 16 is of unit height (vertical dimension) and width (horizontal dimension), and all its dimensions are given as fractions of these units. A magma chamber of circular cross section, with a diameter of 0.30 units, has its centre at a depth of 0.45 units from the top of the model (the rift-zone surface) and thus 0.55 units from the bottom of the model. For a typical scaling, where the rift zone is $10 \mathrm{~km}$ thick, the chamber is $3 \mathrm{~km}$ in diameter with a centre at $4.5 \mathrm{~km}$, and a top at $2 \mathrm{~km}$, depth below the surface: these figures are similar to those observed or inferred for active and extinct crustal magma chambers in Iceland (Gudmundsson, 1990, 1998).

The magma chamber is located in a crust where stiffness increases in abrupt steps from 5 $\mathrm{GPa}$ in the topmost layer to $100 \mathrm{GPa}$ in the bottom layer. To emphasise the importance of changes in stiffness, and because variations in Poisson's ratio are commonly much less than those in Young's modulus (Bell, 2000), all the layers have the same Poisson's ratio: 0.25 . The only loading in the model is a magmatic excess pressure (defined in eq. (4.2)) of $10 \mathrm{MPa}$ in the chamber. To avoid rigid body rotation and translation, the model is fastened, using the condition of no displacements (BEASY, 1991), in all the corners.

The results show that tensile stresses are highest around the magma chamber (only contours between 1 and $10 \mathrm{MPa}$ are shown) and fall off with increasing distance from the cham- ber, in agreement with eqs. (4.3) to (4.8). A remarkable feature is that there are no significant tensile stresses transferred to the low-stiffness top layer $A$ of the model. This indicates that this layer would normally act as a stress barrier to the dykes propagating from the magma chamber. Thus, during periods of volcanic unrest with dyke and sheet injection, layer $A$ might arrest many of, or all, the dykes.

Even if the volcanic zone hosting the magma chamber in fig. 16 is subject to extension, it is still difficult for dykes to propagate through layer $A$ and to the surface to feed a volcanic eruption. This is seen in fig. 17 where the model in fig. 16 has been subjected to crustal extension of $3 \mathrm{MPa}$, a value that is thought to be typical during rifting episodes in the upper part of the volcanic zones in Iceland. In this model, the region of high tensile stress (in excess of 10

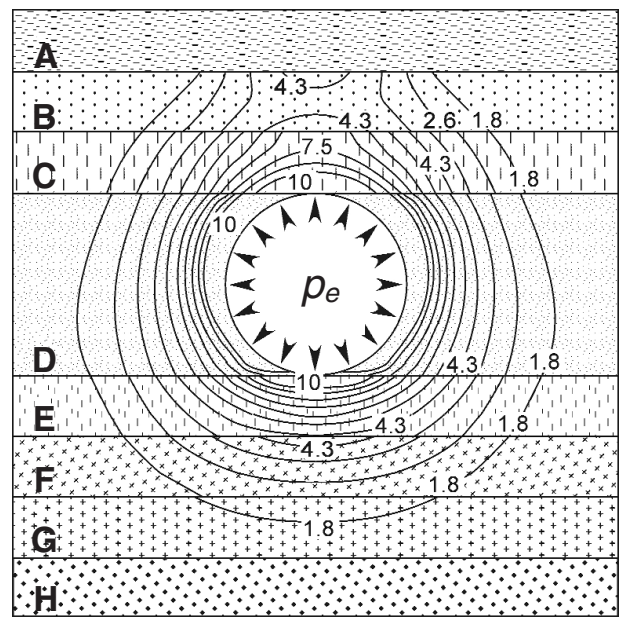

Fig. 16. Boundary-element model showing the contours, in $\mathrm{MPa}$, of the maximum principal tensile stress $\sigma_{3}$ around a magma chamber in a layered crust of a rift zone or a volcanic edifice. The chamber is subject to magmatic excess pressure $p_{e}=10 \mathrm{MPa}$, similar to the laboratory tensile strengths of common rocks. The stiffnesses of the host-rock layers, also based on laboratory measurements (Hansen et al., 1998; Bell, 2000; Nilsen and Palmstrom, 2000), are as follows: $\mathrm{A}=5 \mathrm{GPa} ; \mathrm{B}=$ $20 \mathrm{GPa} ; \mathrm{C}=30 \mathrm{GPa} ; \mathrm{D}=50 \mathrm{GPa} ; \mathrm{E}=70 \mathrm{GPa} ; \mathrm{F}=80$ $\mathrm{GPa} ; \mathrm{G}=90 \mathrm{GPa}$; and $\mathrm{H}=100 \mathrm{GPa}$. 


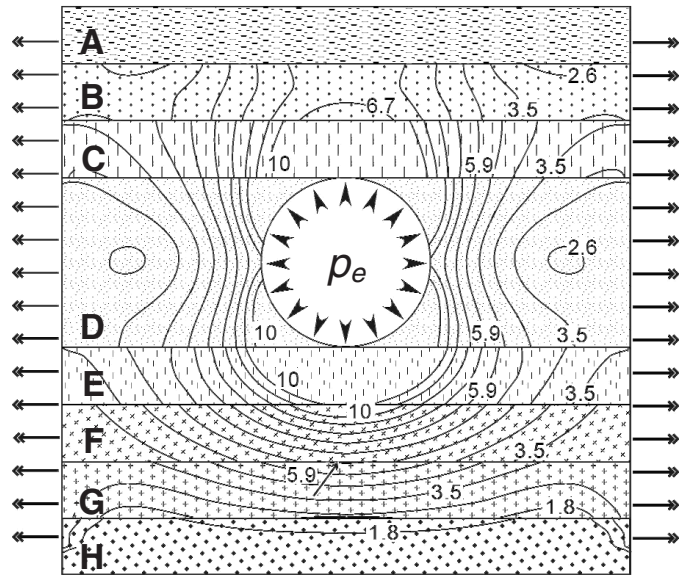

Fig. 17. Boundary-element model showing the contours, in $\mathrm{MPa}$, of the maximum principal tensile stress around a magma chamber in a layered crust of a rift zone or a volcanic edifice. The model and layering is the same as in fig. 16 except that in addition to the magmatic excess pressure of $10 \mathrm{MPa}$ there is a uniform horizontal tension, as indicated by the horizontal arrows, of $3 \mathrm{MPa}$. This tension would apply to plate pull in rift zones and volcano spreading in edifices.

$\mathrm{MPa}$ ) around the magma chamber is much larger than that in the model in fig. 16 and extends all the way through layers $C$ (above the chamber) and $E$ (below the chamber). There are tensile stresses throughout the lower part of the crust (the lowermost part of the model is fastened, using the no-displacement conditions, which explains the fall-off in tensile stress in layer $H$, despite is high stiffness). The high tensile stresses in layers $C$ and $B$, above the magma chamber, indicate that dykes would normally easily propagate through those layers. Again, however, the dykes would tend to become arrested in the soft surface layer $A$.

The results of the models in figs. 16 and 17 thus generally support the analytical results that during extension and rifting dyke injection is encouraged in stiff layers, but dyke arrest is encouraged in soft layers (Gudmundsson and Brenner, 2001). These results should not, however, be taken to indicate that no dykes can propagate through soft layers. Tensile stresses are not needed in these layers for at least some dykes to be able to propagate to the surface. However, the lack of significant tensile stresses, even during periods of active rifting (fig. 17), indicates that only few dykes, at most, would be able to propagate through the surface layer $A$ so long as it has such a low stiffness. Thus, the stress situation in a layered crust where the stiffness gradually increases with depth and, in particular, where there is a very soft layer at the surface, encourages dyke arrest in the uppermost part of the crust.

\section{Surface effects of arrested dykes}

Surface deformation in volcanic rift zones and edifices is routinely used to infer the geometry and shape of emplaced magmafilled fractures, sheets and dykes during periods of unrest (e.g., Jousset et al., 2003). The methods and models used to make these inferences are very important for assessing volcanic hazards and must be highly reliable.

Analytical solutions for surface effects of an extension fracture (such as a dyke) have existed for many years; one of the oldest is the one by Isida (1955). For a vertical extension fracture subject to tension or internal fluid overpressure there will be surface tensile stress concentration to either side of the fracture, and no concentration right above the fracture tip. Later papers that deal explicitly with the surface effects of emplaced dykes include those of Pollard et al. (1983), Okada (1985), Rubin and Pollard (1988), Bonafede and Olivieri (1995), Bonafede and Danesi (1997), and Bonafede and Rivalta (1999a,b). Generally, these works agree with the results of Isida (1955), except that the early work of Pollard and Holzhausen (1979) indicated a significant graben formation above the dyke, implying subsidence of the ground surface above the dyke tip, but this conclusion was changed in later papers (Pollard et al., 1983; Rubin and Pollard, 1988).

Except for the models by Bonafede and Rivalta (1999a,b), all these models assume a homogeneous, isotropic elastic material. There are two main problems with these types of models 
for volcanic edifices and rift zones. The first is that it is difficult to explain how the dykes became arrested in the first place. Whether the dyke is modelled as an elliptic hole or a mathematical crack (with a linear or constant magma overpressure), so long as there is any significant overpressure in the dyke, there will be very high tensile stresses at the dyke tip (normally much higher than any induced surface stresses), and difficult to see how the dyke should become arrested.

The second difficulty is that while the homogeneous and isotropic model may be a reasonable approximation at great depths in an old crust, it is definitely a poor model of the uppermost part of the crust in active rift zones and edifices. As was discussed earlier, such a crust normally consists of alternating pyroclastic layers and lava flows (fig. 1), of strongly contrasting mechanical properties and with weak or even open layer contacts (fig. 2).

To illustrate the first difficulty, consider the simplest model of an arrested dyke in a vertical section, namely an elliptical hole of a dip (height) dimension $2 \mathrm{a}$. If the radius of curvature of the dyke tip is $r_{c}=b^{2} / a$, where the dyke thickness (opening) is $2 b$, and the dyke is subject to a constant magmatic overpressure $P_{0}$, then the maximum tensile (minimum compressive) principal stress $\sigma_{3}$ at the dyke tip is

$$
\sigma_{3}=-P_{0}\left[2\left(\frac{a}{r_{c}}\right)^{1 / 2}-1\right]
$$

where the magmatic overpressure is defined as the total magma pressure minus the dyke-normal compressive stress.

For dykes that end in vertical sections, typical radii of curvature of their tips are a few centimetres (figs. 4, 7 and 8). When the dyke dip dimension $a$ reaches many kilometres, as is common, eq. (5.1) yields theoretical tensile stresses at the dyke tip as $\sim 10^{3}-10^{4}$ $\mathrm{MPa}$. In case the radius of curvature refers only to individual dyke segments, with lengths from tens of metres to a hundred metres (Gudmundsson, 1995), rather than whole dykes, eq. (5.1) still yields theoretical dyketip tensile stresses of $\sim 10^{2}-10^{3} \mathrm{MPa}$. The the- oretical tensile stresses at the tips of dykes, as estimated from eq. (5.1), are thus from a hundred to several thousand times greater than situ tensile strengths (0.5-6 MPa) of common host rocks.

A dyke can also be modelled as a two-dimensional mathematical crack (Gudmundsson, 2002; Gudmundsson et al., 2002). If the mathematical crack that the dyke occupies is located on the vertical $y$-axis and defined by $x=0,-a \leq y \leq a$, then the magma overpressure is given by the even function $p(y)=$ $=p(-y)$; this ensures that the magma overpressure is the same on the dyke walls above and below the horizontal $x$-axis. Based on field observations, a dyke should normally be modelled as an extension fracture (a mode I crack). For a uniform magmatic overpressure $p(y)=P_{0}$, the dyke-normal stress inside the dyke is the maximum principal tensile stress $\sigma_{3}=-P_{0}$, for $0 \leq y \leq a$, whereas outside the dyke tips, for $y>a$, the tensile stress $\sigma_{3}(\mathrm{y}, 0)$ is (Sneddon, 1973; Maugis, 2000; Gudmundsson, 2002)

$$
\sigma_{3}=-P_{0} y\left[\frac{1}{\left(y^{2}-a^{2}\right)^{1 / 2}}-\frac{1}{y}\right] .
$$

It follows from eq. (5.2) that when $y$ approaches (from outside the dyke tip), the tensile stress $\sigma_{3}$ at the tip becomes infinite.

For some dykes, the magmatic overpressure $p(y)$ may not be uniform but rather vary inside the dyke. For example, the overpressure may vary from a maximum value of $P_{0}$ at the vertical dyke centre by a linear gradient $p_{1} y$ (here treating $y$ as an absolute value) according to the equation

$$
p(y)=P_{0}+p_{1} y .
$$

Then it follows (Gudmundsson et al., 2002) that the maximum principal tensile stress $\sigma_{3}$ at the dyke tip is:

$\sigma_{3}=-\frac{2 p_{1}}{\pi}\left[\frac{y a}{\left(y^{2}-a^{2}\right)^{1 / 2}}-y \sin ^{-1} \frac{a}{y}\right]$

so that when $y$ approaches $a$, the tensile stress $\sigma_{3}$ at the dyke tip is again infinite. The mathe- 
matical crack model thus indicates that in a small region around the dyke tip the tensile stress in the host rock is infinite, representing a stress singularity. Non-elastic (permanent) deformation and microcracking at the dyke tip relieve part of the stress (thereby making the stress less than infinite); nevertheless, the mathematical crack models in eqs. (5.2) and (5.3) predict very high tensile stresses at a typical dyke tip in a homogeneous, isotropic crust.

It follows from eqs. (5.1), (5.2) and (5.4) that, irrespective of whether the dyke is modelled as an elliptic hole or a mathematical crack, for dykes with any significant overpressure in a homogeneous and isotropic host rock there will be potentially very high tensile stresses at the dyke tips. A dyke with any significant overpressure should, therefore, not become arrested in such a crust. Thus, for a dyke tip to become arrested at a certain crustal depth, rather than propagating to the surface of the rift zone, the dyke overpressure must either be zero or, alternatively, the host rock must be heterogeneous and anisotropic so as to have stress barriers, transverse discontinuities, or an abrupt change in layer stiffnesses. These features are common in a layered crust, but then the stress fields associated with arrested dyke tips may be very different from that suggested for a homogeneous, isotropic crust.

We shall illustrate stress fields generated by arrested dykes in a layered crust, and in particular the stresses at the surface of the associated rift zone (or a volcanic edifice), using the boundaryelement model BEASY (1991). The magmatic overpressure in all the models has a linear variation from $10 \mathrm{MPa}$ at the dyke bottom to $0 \mathrm{MPa}$ at the dyke tip. Consider first the effects of stress barriers, that is, layers where the stress field is unfavourable for the propagation of a particular type of fracture. For dykes, stress barriers are, as explained above, layers where there is an unusually high dyke-normal compressive stress.

These barriers usually suppress much of, or all, the tensile stresses associated with the dyke tip and allow very small, if any, stresses to be transferred to the surface. Consider, for example, a barrier with $7 \mathrm{MPa}$ compressive stress, as has been measured in Iceland (Haimson and Rummel, 1982), at $1 \mathrm{~km}$ depth whereas the dyke tip is at $3 \mathrm{~km}$ depth below the surface (fig. 18). All the layers have the same stiffness, $40 \mathrm{GPa}$.
The maximum tip tensile stress is $50 \mathrm{MPa}$ (the highest contour shown is $5 \mathrm{MPa}$ ) but no tensile stress is transferred to the surface.

Consider next the effects of variation in stiffness in a layered crust on the surface stresses associated with an arrested dyke (fig. 19). Here the horizontal compressive stress increases linearly with depth, from 0 to $20 \mathrm{MPa}$ at $0.8 \mathrm{~km}$ depth, in accordance with the increase in overburden pressure (vertical stress). The dyke tip is at $1 \mathrm{~km}$ depth, and above is a layer (200 m thick) with zero compressive stress, supposed to be due to an earlier extension or to be a soft sediment acting as a soft inclusion that takes on little or no horizontal compressive stress. This layer just magnifies the dyke-tip tensile stress, but does not oth-

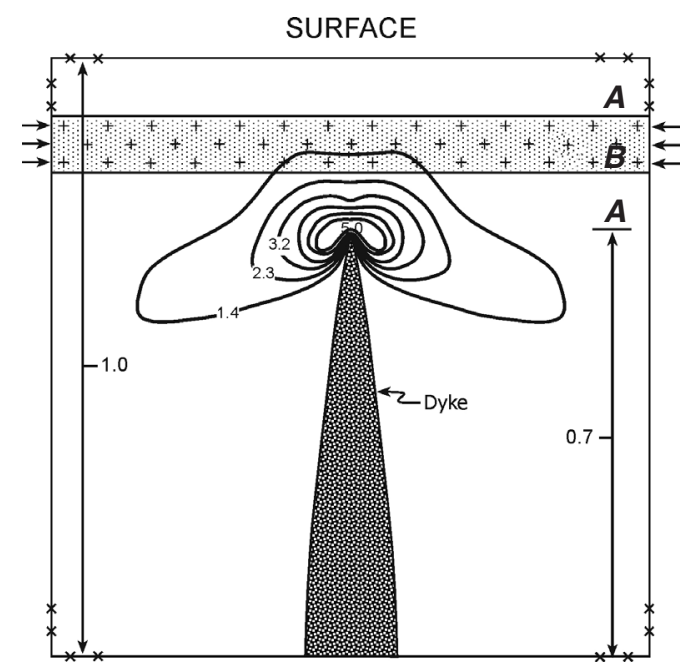

Fig. 18. Boundary-element model showing the contours, in $\mathrm{MPa}$, of the maximum principal tensile stress $\sigma_{3}$ around a dyke tip located at $3 \mathrm{~km}$ below the surface of a rift zone or a volcanic edifice. Layer $B$ is a stress barrier with excess horizontal compressive stress of $7 \mathrm{MPa}$; this layer extends from a depth of 1 $\mathrm{km}$ to $2 \mathrm{~km}$ below the surface. The stiffnesses and Poisson's ratios of layers $A$ and $B$ are uniform, 40 $\mathrm{GPa}$ and 0.25 , respectively. The contours of $\sigma_{3}$ flatten out under the stress barrier and no dyke-induced tensile stresses reach the surface. In this and the models in figs. 19 and 20, the dyke thickness (opening), as obtained from the numerical models, is not to scale when compared with the crustal thickness. 

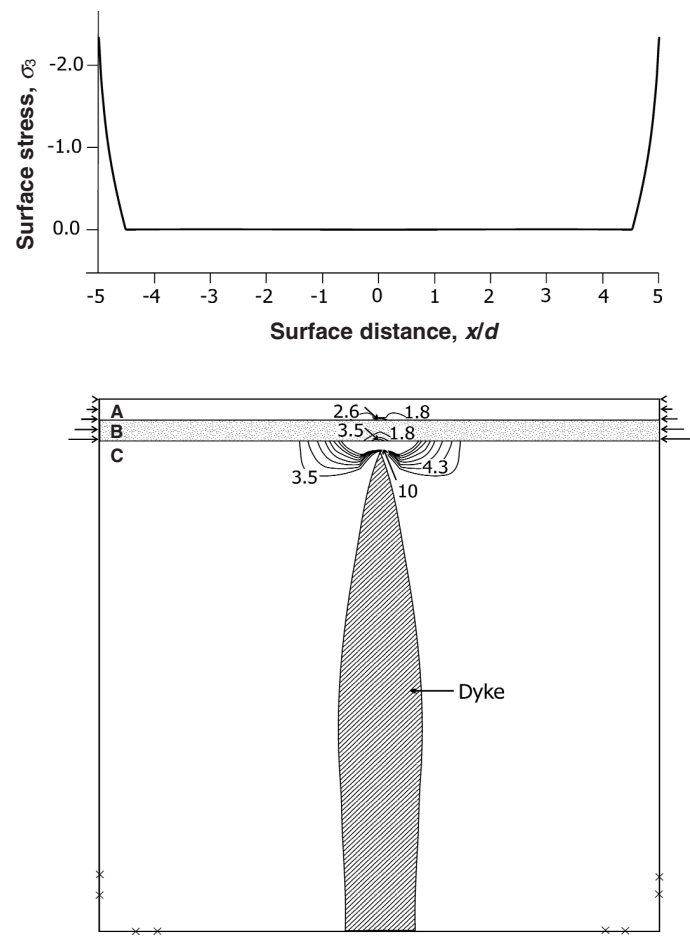

Fig. 19. Boundary-element model of a dyke with a tip at $1 \mathrm{~km}$ depth below the surface of a rift zone or a volcanic edifice where the horizontal stress increases linearly (with overburden pressure) from $0 \mathrm{MPa}$ to 20 $\mathrm{MPa}$ at $0.8 \mathrm{~km}$ depth, as indicated by horizontal arrows ( $c f$. Gudmundsson, 2003). Layer $B$ is soft ( $E=$ $5 \mathrm{GPa}$ ), whereas the other layers are moderately stiff $(E=40 \mathrm{GPa})$. The contours show the values between 1 and $10 \mathrm{MPa}$ of the maximum principal tensile stress. The upper diagram shows that there is no dyke-induced tensile stress at the surface above the dyke (the margin stresses are irrelevant because they relate to the non-physical boundary conditions in the model). This is because layer $B$, which takes up very little tensile stress, hinders stress transfer to the surface layer $A$. The lower diagram shows the tensile stress concentration at the dyke tip, the maximum value being $=$ $102 \mathrm{MPa}$ (cf. eqs. (5.1), (5.2) and (5.4)).

erwise affect the conclusions of the model calculations. Layers $A$ and $C$ are moderately stiff, 40 $\mathrm{GPa}$, corresponding to common basaltic lava flows, whereas layer $B$ is soft, $5 \mathrm{GPa}$, corresponding to many young hyaloclastites or sedimenta- ry layers. It is a large-scale version of the layering in fig. 7 from the Reykjanes Peninsula.

Even if the maximum calculated dyke-tip tensile stresses are $102 \mathrm{MPa}$, very little tensile stresses are transferred to the soft layer and the surface layer is unstressed (fig. 19). There are thus no dyke-induced tensile stresses at the surface. The marginal tensile-stress values are due to the fastening of the model at the corners and have no physical meaning.

Consider next the effects of a discontinuity, say a weak contact between layers in the upper part of a rift zone (or a volcanic edifice). Dykes tend to open up such contacts and are very commonly affected by them; many dykes become arrested at the open contacts, change into sills, or become offset across them. A dyke may follow the contact for several metres (fig. 11), occasionally tens of metres, and then leave the contact to continue its vertical propagation into the lava pile above. In this model (fig. 20), the layering is the same as in the last model (fig. 19), but there is a weak discontinuity, a contact, modelled as an internal spring with stiffness $6 \mathrm{MPa} / \mathrm{m}$, between layers $A$ and $B$. The contact is $8 \mathrm{~km}$ wide, similar to the width of many Holocene volcanic systems in Iceland (fig. 5). To estimate the maximum effects that the contact may have on the surface stresses, we subject the layers neither to overburden pressure nor horizontal compressive stress. Effectively, this would mean that in the uppermost $800 \mathrm{~m}$ of the rift zone extension had reduced all compressive stresses to zero. This boundary condition is not very likely to be commonly satisfied, but is used here so as to maximise the potential surface effects of the arrested dyke.

The central part of the contact opens up (fig. 20). However, even if the calculated dyke-tip tensile stress is $174 \mathrm{MPa}$, there are very little tensile stresses at the surface above the dyke itself (fig. 20). The main tensile stresses at the surface, occur above the lateral ends of the contact, at a distance of $4 \mathrm{~km}$ to either side of the dyke tip. There are tensile stresses are low, only $2 \mathrm{MPa}$ and unlikely to lead to much fracture formation. Similar results were obtained in several other models: there are little or no tensile stresses in a large surface area above the dyke itself, only above the lateral ends of the weak contact. 
The results in this section indicate, first, that the tensile stress at a dyke tip is normally much greater than any dyke-induced tensile stress at the surface. It is thus not clear why the tip of a
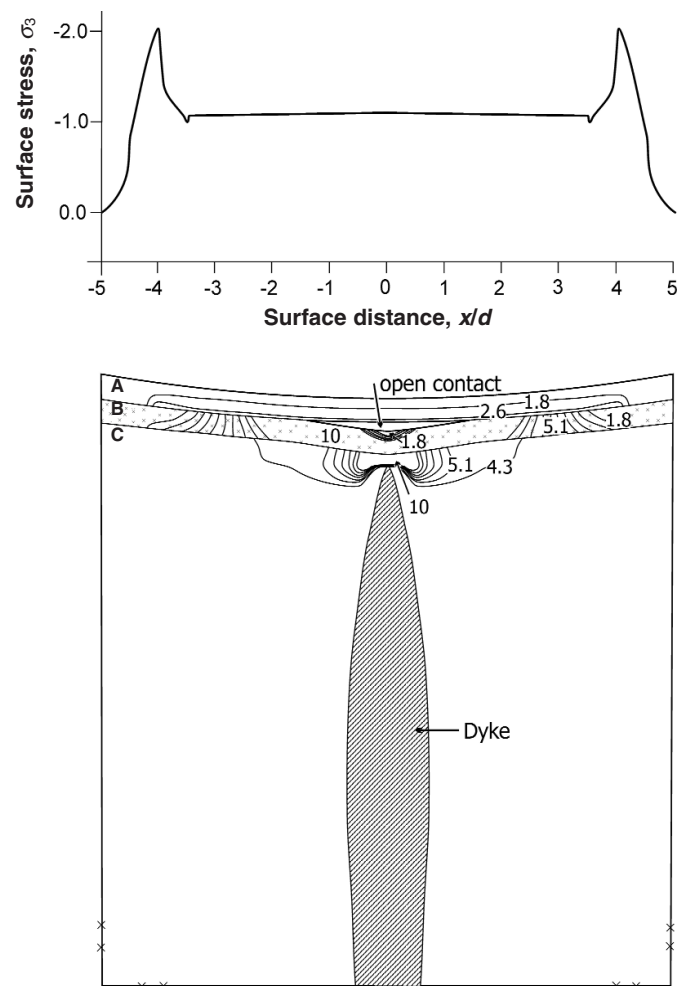

Fig. 20. Boundary-element model of a dyke with a tip at $1 \mathrm{~km}$ depth below the surface of a rift zone or a volcanic edifice ( $c f$. Gudmundsson, 2003). The upper contact between layers $A$ and $B$, at $0.4 \mathrm{~km}$ depth, is weak and modelled as an internal spring with a stiffness of $6 \mathrm{MPa} / \mathrm{m}$. This contact opens up when the dyke tip approaches. The contours show the values between 1 and $10 \mathrm{MPa}$ of the maximum principal tensile stress $\sigma_{3}$. The upper diagram shows that there is little dyke-induced tensile stress at the surface above the dyke. However, there are higher tensile stresses at the margins but these occur above the lateral ends (at roughly $4 \mathrm{~km}$ to either side of the dyke) of the weak contact at $0.4 \mathrm{~km}$ depth. The lower diagram shows the tensile stress concentration at the dyke tip, the maximum value being $\sigma_{3}=174$ $\mathrm{MPa}$ (cf. eqs. (5.1), (5.2) and (5.4)) dyke that is supposed to be able to induce large tensile (and shear) stresses at the surface should become arrested. Secondly, the results show that for an active rift zone or a volcanic edifice, straightforward inversion of geodetic data to infer the geometry and depth to an emplaced dyke may yield very unreliable results.

\section{Discussion}

The results of field observations and analytical and numerical models presented in this paper suggest that the conditions for sheet and dyke arrest or, alternatively, their propagation to the surface, are primarily controlled by the local stress fields in the rift zone or volcanic edifice. Most volcanic edifices consist of layers of contrasting mechanical properties, such as soft pyroclastic layers and stiff lava flows. The present, as well as earlier (Gudmundsson, 2002, 2003), numerical models indicate that such edifices commonly develop stress fields that encourage dyke arrest.

Surface deformation studies are routinely used to infer the geometry of dykes that become arrested during periods of volcanic unrest (Pollard et al., 1983; Jousset et al., 2003). Most models used in inversion of the surface data to infer dyke geometries assume that the rock hosting the dykes may be modelled as a homogeneous, isotropic half space and imply that the host-rock stresses are uniform. Our results indicate that, for such a host rock, it remains to be explained how a dyke is able to induce large tensile (and shear) stresses and cause fracturing at the surface of a rift zone while becoming arrested - given that the dyke-tip tensile stresses would normally be much greater than any induced surface stresses and thus greater than the in situ tensile strength of the host rock. Also, some theoretical models based on these assumptions predict that arrested dykes may generate major grabens at the surfaces of rift zones and volcanic edifices. In this paper we summarise field observations showing that arrested dyke tips in eroded rift zones are normally not associated with grabens or normal faults that could be generated by dyke-induced stresses. Our field results also show that some dykes that are arrested within a few metres of the surface do not generate faults or grabens at the surface (fig. 8). 
Our numerical models and field data suggest that this discrepancy between some theoretical models and field observations may be explained by the mechanical layering of the crust.

The numerical models presented here and in earlier papers show that abrupt changes in Young's moduli, layers with relatively high dykenormal compressive stresses (stress barriers), and weak, horizontal contacts have large effects on local stresses in rift zones and volcanic edifices. In particular, the models in figs. 16 and 17, and earlier numerical models (Gudmundsson, 2002; Gudmundsson et al., 2002), indicate that during periods of magma-chamber inflation and associated ground deformation in volcanic areas there may be faulting (with associated seismicity and changes in the hydrothermal fields) in stiff layers while all the injected dykes become arrested in soft layers (so that no eruptions occur). Observations of this kind are well known from many active volcanoes, particularly calderas (Bjornsson, 1984; De Natale et al., 1997).

As to ground deformation related to dykes, the numerical models considered (figs. 18-20) indicate that the surface tensile stresses induced by arrested dykes are commonly too small to lead to significant fault or graben formation at the rift-zone surface. The only significant dykeinduced surface tensile stresses $(2 \mathrm{MPa})$ in these models are for a dyke tip arrested at $1 \mathrm{~km}$ depth below the surface of a rift zone with a weak contact at $400 \mathrm{~m}$ depth and subject to extension (fig. 20). These tensile stresses, however, peak above the ends of the weak horizontal contact which, in the model considered, occur at distances of $4 \mathrm{~km}$ to either side of the dyke and do not show any simple relation to the dyke geometry or the depth to the dyke tip. Thus, for a layered crust with weak contacts, straightforward inversion of surface geodetic data may lead to unreliable geometries of dykes.

In this paper, we focus on dyke arrest due to local, unfavourable stresses. There are, however, various ways by which the stress conditions favouring dyke arrest in a volcanic edifice or a rift zone may be changed to conditions favouring dyke propagation to the surface and thus the formation of feeder dykes. These include i) stiff surface layers, ii) gradual increase in stiffness with burial, and iii) stress-field homogenisation.
When new lava flows are erupted, particularly thick basaltic lava flows, the stiffness of the uppermost part of the crust increases. As a consequence, layer $A$ in the models in figs. 16 and 17 would become relatively stiff, and thus be less likely to arrest dykes. However, once an overpressured dyke has propagated to the surface through the surface layer, in particular during a rifting episode with the formation or development of tension fractures and normal faults, the stiff lava flow A at the surface of the rift zone may act as a stress barrier for subsequent dykes (Gudmundsson and Brenner, 2001). This follows because dyke injection, tension fracture formation, and normal faulting all increase the temporary horizontal compressive stress in the layer; and this compressive stress must be relaxed (e.g., through plate pull) before the next dyke can propagate through the layer to the surface to feed an eruption.

One reason that the stiffnesses of layers increase with time and burial in active volcanic areas is hydrothermal alteration and precipitation of secondary minerals. Hydrothermal alteration generally encourages welding together (healing and sealing) of layer contacts, making the entire pile gradually approach that of a single, thick layer. As a consequence of these processes, not only does the layer stiffness increase, but also its density; as is well known, density and stiffness are positively related (Jaeger and Cook, 1979). In particular, the initially soft scoria (pyroclastic) layers at the contacts between lava flows are common pathways for hydrothermal water and thus the sites of much secondary mineralisation. These, initially soft, layers gradually approach the stiffnesses of the adjacent stiffer parts of the lava flows. It follows that the hydrothermal alteration makes the lava pile in an active volcanic zone gradually more uniform in stiffness, thereby encouraging stress-field homogenisation.

Stress-field homogenisation means that the stress field along a potential pathway of a fracture, such as a dyke, gradually becomes uniform (Gudmundsson and Homberg, 1999). In a volcanic zone, stress-field homogenisation is, as indicated above, partly achieved by hydrothermal alteration of the lava pile above the magma sources. Partly, however, the stress-field homogenisation is achieved through dyke injection and faulting of the lava pile. For example, fault- 
ing reduces the stress differences along the potential pathway of a dyke. And previous dyke injections make the stress field more uniform along the pathways of subsequent dykes. It is proposed that during a stress cycle, which corresponds to the time between successive eruptions (a volcanic cycle), a magma chamber gradually homogenises the surrounding stress field until one or more potential dyke pathways have been homogenised all the way to the surface, in which case one or more eruptions may occur. The homogenised condition is thus not satisfied during most volcanic unrest periods which explains why, even if they lead to dyke and sheet injection, most such periods do not result in volcanic eruptions.

\section{Conclusions}

In the model presented in this paper there are two basic mechanisms by which dykes and sheets become arrested in volcanoes: stress barriers and rock anisotropy, such as those associated with discontinuities. These mechanisms are related, particularly through changes in stiffnesses. Such changes are common at contacts (discontinuities) between different rock types.

This model explains, first, why many dykes become arrested (commonly with blunt tips) at contacts and, second, why dykes commonly taper away in homogeneous layers. The model indicates that during most volcanic unrest periods with sheet or dyke injections, the probability of an eruption is low. Only during those rare unrest periods when the stress field has been homogenised all the way to the surface are eruptions to be expected.

Some theoretical models predict that arrested dykes may generate major grabens at rift-zone surfaces. But most arrested dyke tips (even very shallow ones) in rift zones do not generate normal faults or grabens. Most of these models assume the crust to be homogeneous and isotropic. Because dyke-tip tensile stresses are much larger than the dyke-induced surface stresses, it is unclear in such models why the tip of a dyke supposed to generate large surface stresses becomes arrested.

When crustal layering is taken into account, numerical models show that abrupt changes in Young's moduli, stress barriers and weak con- tacts greatly affect the dyke-induced stresses. The numerical models presented in this paper indicate that layering commonly suppresses dykeinduced tensile (and shear) stresses at the surface, making fracture, fault and graben formation less likely. Weak contacts lower surface stresses and transfer the stress peaks to the lateral contact ends, in which case straightforward inversion of surface geodetic data to infer geometries of arrested dykes may yield unreliable results. It is concluded that local stress fields unfavourable to dyke propagation to the surface (and eruption) may change to favourable stress fields through several processes, the most important of which is stress-field homogenisation.

\section{Acknowledgements}

This work was supported through several grants from the Norway Research Council, the European Commission (through the Prepared project), as well as through a $\mathrm{PhD}$ grant from Statoil (to Agust Gudmundsson) for Sonja L. Brenner. We thank Sergio Vinciguerra for helpful review comments.

\section{REFERENCES}

Amadei, B. and O. Stephansson (1997): Rock Stress and its Measurement (Chapman and Hall, New York).

BEASY (1991): The Boundary Element Analysis System User Guide (Computational Mechanics, Boston).

Bell, F.G. (2000): Engineering Properties of Soils and Rocks (Blackwell, Oxford).

BJornsson, A. (1984): Dynamics of crustal rifting in NE Iceland, J. Geophys. Res., 90, 10151-10162.

BONAFEDE, M. and S. DANESI (1997): Near-field modifications of stress induced by dyke injection at shallow depth, Geophys. J. Int., 130, 435-448.

BONAFEDE, M. and M. OlIVIERI (1995): Displacement and gravity-anomaly produced by a shallow vertical dyke in a cohesionless medium, Geophys. J. Int., 123, 639-652.

BONAFEDE, M. and E. Rivalta (1999a): On tensile cracks close to and across the interface between two welded elastic half-spaces, Geophys. J. Int., 138, 410-434.

BonAfEDE, M. and E. Rivalta (1999b): The tensile dislocation problem in a layered elastic medium, Geophys. J. Int., 136, 341-356.

Brebila, C.A. and J. Dominguez (1992): Boundary Elements, an Introductory Course (Computational Mechanics, Boston).

De Natale, G. and F. Pingue (1993): Ground deformations in collapsed caldera structures, J. Volcanol. Geotherm. Res., 57, 19-38. 
De Natale, G., S.M. Petrazzuoli and F. Pingue (1997): The effect of collapse caldera structures on ground deformation in calderas, Geophys. Res. Lett., 24, 1555-1558.

DileK, Y., E.M. Moores and H. Furnes (1998): Structure of modern oceanic crust and ophiolites and implications for faulting and magmatism at ocean spreading centers, in Faulting and Magmatism at Mid-Ocean Ridges, edited by W.R. Buck, P.T. Delaney, J.A. KarSON and Y. LAGABRIELLE (American Geophysical Union, Washington), 219-265.

Gudmundsson, A. (1990): Emplacement of dikes, sills and crustal magma chambers at divergent plate boundaries, Tectonophysics, 176, 257-275.

GudMundsson, A. (1995): Infrastructure and mechanics of volcanic systems in Iceland, J. Volcanol. Geotherm. Res., 64, 1-22.

Gudmundsson, A. (1998): Magma chambers modeled as cavities explain the formation of rift zone central volcanoes and their eruption and intrusion statistics, $J$. Geophys. Res., 103, 7401-7412.

Gudmundsson, A. (2000): Dynamics of volcanic systems in Iceland: example of tectonism and volcanism at juxtaposed hot spot and mid-ocean ridge systems, Ann. Rev. Earth Planet. Sci., 28, 107-140.

GudMundSSON, A. (2002): Emplacement and arrest of sheets and dykes in central volcanoes, J. Volcanol. Geotherm. Res., 116, 279-298.

Gudmundsson, A. (2003): Surface stresses associated with arrested dykes in rift zones, Bull. Volcanol., 65, 606619.

Gudmundsson, A. and S.L. Brenner (2001): How hydrofractures become arrested, Terra Nova, 13, 456-462.

Gudmundsson, A. and C. Homberg (1999): Evolution of stress fields and faulting in seismic zones, Pure Appl. Geophys., 154, 257-280.

Gudmundsson, A., I. FueldskaAR and S.L. BREnNER (2002): Propagation pathways and fluid transport of hydrofractures in jointed and layered rocks in geothermal fields, J. Volcanol. Geotherm. Res., 116, 257-278.

HAimson, B.C. and F. RuMmel (1982): Hydrofracturing stress measurements in the Iceland research drilling project drill hole at Reydarfjordur, Iceland, J. Geophys. Res., 87, 6631-6649.

HANSEN, S.E., T. SORLOKK and A.E. JoHANnESSON (1998): Mechanical Properties of Rocks (Sintef, Trondheim), (in Norwegian).

Harris, A.J.L., J.B. Murray, S.E. Aries, M.A. Davies, L.P. Flynn, M.J. Wooster, R. Wright and D.A. RoTHERY (2000): Effusion rate trend at Etna and Krafla and their implications for eruptive mechanisms, J. Volcanol. Geotherm. Res., 102, 237-270.

IsIDA, M. (1955): On the tension of a semi-infinite plate with an elliptic hole, Tech. Rep. Fac. Eng., Tokushina Univ., 5, 75-95.

JAEGER, J.C. and N.G.W. CooK (1979): Fundamentals of Rock Mechanics (Chapman \& Hall, London).

JING, L. and J.A. HuDSON (2002): Numerical methods in rock mechanics, Inte. J. Rock Mech. Min. Sci., 39, 409-427.

Jousset, P., H. Mori and H. OKADA (2003): Elastic models for the magma intrusion associated with the 2000 eruption of Usu Volcano, Hokkaido, Japan, J. Volcanol. Geotherm Res., 125, 81-106.
KARSON, J.A. (1998): Internal structure of oceanic lithosphere: a perspective from tectonic windows, in Fault ing and Magmatism at Mid-Ocean Ridges, edited by W.R. Buck, P.T. DElaney, J.A. Karson and Y LAGABRIELLE (American Geophysical Union, Washington), pp. 177-218.

MarinONI, L.B. and A. GudMundsson (2000): Dykes, faults and palaeostresses in the Teno and Anaga massifs of Tenerife (Canary Islands), J. Volcanol Geotherm. Res., 103, 83-103.

Maugis, D. (2000): Contact, Adhesion and Rupture of Elastic Solids (Springer-Verlag, Berlin).

Nilsen, B. and A. Palmstrom (2000): Engineering Geology and Rock Engineering, Handbook 2, The Rock Mechanics Group, Oslo.

OKADA, Y. (1985): Surface deformation due to shear and tensile faults in a half-space, Bull. Seismol. Soc. Am. 75, 1135-1154.

PAllister, J.S. (1981): Structure of the sheeted dike complex of the Samail ophiolite near Imbra, Oman, $J$. Geophys. Res., 86, 2661-2672.

PALmason, G. (1971): Crustal structure of Iceland from explosion seismology, Societas Scientiarum Islandica Rit, 40, 1-187.

Pedersen, R.B. (1986): The nature and significance of magma chamber margins in ophiolites: examples from the Norwegian Caledonides, Earth Plan. Sci. Lett., 77, 100-112.

Pollard, D.D. and G. Holzhausen (1979): On the mechanical interaction between a fluid-filled fracture and the earth's surface, Tectonophysics, 53, 27-57.

Pollard, D.D., P.T. Delaney, W.A. Duffield, E.T. Endo and A.T. OKAMURA (1983): Surface deformation in volcanic rift zones, Tectonophysics, 94, 541-584.

Rubin, A.M. and D.D. Pollard (1988): Dike-induced faulting in rift zones of Iceland and Afar, Geology, 16, 413-417.

SAadA, A.S. (1983): Elasticity: Theory and Applications (Krieger, Malabar, Florida).

SCHULTZ, R.A. (1995): Limits on strength and deformation properties of jointed basaltic rock masses, Rock Mech. Rock Eng., 28, 1-15.

SigurgeIRSSON, M.A. (1995): The Younger Stampa Eruption on the Reykjanes Peninsula (in Icelandic), Natturufraedingurinn (Reykjavik), 64, 211-230.

SNEDDON, I.N. (1973): Integral Transform Methods, in Methods of Analysis and Solutions of Crack Problems, edited by G.C. SIH (Nordhoff, Leyden), 315-367.

Staples, R.K., R.S. White, B. Brandsdottir, W. MenKe, P.K.H. MaguiRe and J.H. McBride (1997): Faroe-Iceland Ridge Experiment 1, crustal structure of Northeastern Iceland, J. Geophys. Res., 102, 7849-7866.

TAda, H., P.C. Paris and G.R. IRwIN (2000): The Stress Analysis of Cracks Handbook (Del Research Corporation, Hellertown, Pennsylvania), 3rd edition.

Thordarson, T. and S. SelF (1993): The Laki (Skaftar Fires) and Grimsvotn eruptions in 1783-1785, Bull. Volcanol., 55, 233-263.

Timoshenko, G.P. and J.N. Goodier (1970): Theory of Elasticity (McGraw-Hill, London).

WALKER, G.P.L. (1963): The Breiddalur Central Volcano Eastern Iceland, $O$. J. Geol. Soc. London, 119, 29-63. 